\title{
DNA methylation directs nucleosome positioning in RNA-mediated transcriptional silencing
}

M. Hafiz Rothi ${ }^{1, \$}$, Shriya Sethuraman ${ }^{2, \$}, J^{2}$ kub Dolata ${ }^{1,3}$, Alan P Boyle ${ }^{4,5}$, Andrzej T Wierzbicki ${ }^{1, *}$

${ }^{1}$ Department of Molecular, Cellular, and Developmental Biology, University of Michigan, Ann Arbor, MI 48109, USA

${ }^{2}$ Bioinformatics Graduate Program, University of Michigan, Ann Arbor, MI 48109, USA

${ }^{3}$ Department of Gene Expression, Adam Mickiewicz University, Poznań, Poland

${ }^{4}$ Department of Computational Medicine and Bioinformatics, University of Michigan, Ann Arbor, MI 48109, USA

${ }^{5}$ Department of Human Genetics, University of Michigan, Ann Arbor, MI 48109, USA

$\$$ co-first authors

*corresponding authorwierzbic@umich.edu 


\begin{abstract}
Repressive chromatin modifications are instrumental in regulation of gene expression and transposon silencing. In Arabidopsis thaliana, transcriptional silencing is performed by the RNA-directed DNA methylation (RdDM) pathway. In this process, two specialized RNA polymerases, Pol IV and Pol V, produce non-coding RNAs, which recruit several RNA-binding proteins and lead to the establishment of repressive chromatin marks. An important feature of chromatin is nucleosome positioning, which has also been implicated in RdDM. We show that RdDM affects nucleosomes via the SWI/SNF chromatin remodeling complex. This leads to the establishment of nucleosomes on methylated regions, which counteracts the general depletion of DNA methylation on nucleosomal regions. Nucleosome placement by RdDM has no detectable effects on the pattern of DNA methylation. Instead, DNA methylation by RdDM and other pathways affects nucleosome positioning. We propose a model where DNA methylation serves as one of the determinants of nucleosome positioning.
\end{abstract}

\title{
INTRODUCTION
}

Transcriptional gene silencing (TGS) pathways play an important role in maintaining genomic integrity in eukaryotes. This is achieved through repressive chromatin modifications, which are specifically targeted to silence transposable elements (TE) present in the genome. TGS pathways are conserved in fungi, animal and plant kingdoms, denoting their importance in the control of genome stability (Du et al., 2015). In plants, TGS is established and partially maintained through RNA-directed DNA methylation (RdDM), which consists of two major steps, biogenesis of short interfering RNA (siRNA) and de novo DNA methylation (Matzke and Mosher, 2014).

In the first step, RNA polymerase IV (Pol IV) binds to loci targeted for silencing and produces noncoding RNA, which is then converted into a double-stranded form (dsRNA) by RNA-dependent RNA polymerase 2 (RDR2) and cleaved into 24-nucleotide siRNA by DICER-LIKE 3 (DCL3) (Blevins et al., 2015; Law et al., 2013; Mette et al., 1999, 2000; Zhai et al., 2015). siRNAs are then incorporated into ARGONAUTE 4 (AGO4) and other related AGOs, forming AGO-siRNA complexes (Ye et al., 2012). In the second step, RNA polymerase V (Pol V) produces long noncoding RNA (lncRNA) that acts as a scaffold or otherwise helps recruit downstream effectors (Lahmy et al., 2016; Wierzbicki et al., 2008, 2009). The AGO4-siRNA complex is recruited to Pol V-transcribed loci leading to stepwise binding of INVOLVED IN DE NOVO 2 (IDN2) and DOMAINS REARRANGED METHYLTRANSFERASE 2 (DRM2) which deposits DNA methylation (Ausin et al., 2009; Böhmdorfer et al., 2014; Cao and Jacobsen, 2002; Wierzbicki et al., 2009; Zilberman et al., 2003). However, the mechanisms by which DNA methylation and other repressive features of chromatin contribute to transcriptional gene silencing are not fully understood. 
RNA-directed DNA methylation is functionally intertwined with nucleosome modifications and positioning. This includes the involvement of pre-existing histone modification and putative chromatin remodelers in recruitment of both Pol IV and Pol V (Johnson et al., 2014; Law et al., 2013), as well as the establishment of repressive histone modifications and nucleosome positioning in the second step of RdDM (Liu et al., 2016; Stroud et al., 2014; Wierzbicki et al., 2008; Yang et al., 2020a; Zhu et al., 2013). The involvement of active chromatin remodeling in transcriptional silencing by RdDM was suggested by an interaction of IDN2 with SWITCH 3B (SWI3B), a subunit of the Switch/Sucrose Non Fermenting (SWI/SNF) chromatin remodeling complex (Zhu et al., 2013). Subunits of this complex also interact with other silencing factors, including HISTONE DEACETYLASE 6 (HDA6) and MICRORCHIDIA 6 (MORC6), which indicates that SWI/SNF may be involved in various aspects of gene silencing (Liu et al., 2016; Yang et al., 2020a). This is consistent with this complex being multifunctional and affecting not only gene silencing but also various other aspects of plant gene regulation (Archacki et al., 2017; Brzeski et al., 1999; Han et al., 2012; Li et al., 2016; Sacharowski et al., 2015; Sarnowski et al., 2005; Wagner and Meyerowitz, 2002).

There are several indications that nucleosome positioning and DNA methylation are somehow connected throughout plant genomes (Chodavarapu et al., 2010; Huff and Zilberman, 2014; Lyons and Zilberman, 2017). However, the exact nature of this connection varies depending on species and genomic regions tested (Huff and Zilberman, 2014; Lyons and Zilberman, 2017). In Arabidopsis, nucleosomes determined by MNase digestion protections have been reported to generally correlate with DNA methylation (Chodavarapu et al., 2010). However, the opposite correlation exists on a subset of Arabidopsis nucleosomes and throughout genomes of certain other species (Huff and Zilberman, 2014; Lyons and Zilberman, 2017). This difference may be explained by the DNA binding of linker histones, which prevent methylation of linker DNA, and by the activity of DDM1, which facilitates methylation of nucleosomal DNA (Lyons and Zilberman, 2017; Zemach et al., 2013). In Arabidopsis these two proteins counteract the general preference to methylate linker DNA (Lyons and Zilberman, 2017).

The involvement of linker histones, DDM1 and SWI/SNF in determining the pattern of DNA methylation indicates that the observed connection between nucleosomes and DNA methylation is primarily determined by nucleosomes being inaccessible to DNA methyltransferases. This is supported by in vitro data indicating preferential methylation of linker DNA (Felle et al., 2011). However, the opposite relationship has been observed on a few individual loci, where nucleosomes were affected by the $d r m 2$ mutation (Zhu et al., 2013). This indicates that DNA methylation may affect nucleosome positioning. This alternative causality is also supported by some in vitro data (Collings et al., 2013). Therefore, the relationship between nucleosomes and DNA methylation remains only partially resolved. 
Here, we explore the mechanism by which RdDM affects nucleosome positioning in Arabidopsis thaliana. We demonstrate that Pol V and more broadly RdDM affects nucleosomes through the SWI/SNF complex. The SWI/SNF complex is not required for DNA methylation on positioned nucleosomes. Instead, DNA methylation is needed for nucleosome positioning on differentially methylated regions. We propose a model where the RdDM pathway directs nucleosome positioning through DNA methylation to establish transcriptional gene silencing.

\section{RESULTS}

\section{Pol $\mathrm{V}$ affects nucleosomes by a combination of direct and indirect mechanisms}

Pol V has been previously shown to affect protection to MNase digestion of certain genomic regions (Zhu et al., 2013). To conclusively attribute these protections to nucleosome positioning, we expanded this experiment by including immunoprecipitation with an anti-H3 antibody (MNase H3 ChIP-seq) in two biological replicates of Col-0 wildtype and nrpel, a mutant of the largest subunit of Pol V [Figure 1A]. We identified 690 nucleosomes stabilized by Pol V, where signal was at least 2-fold higher in Col-0 compared to nrpel with a false discovery rate (FDR) of less than 0.05 [Figure 1B]. We also identified 3082 Pol V destabilized nucleosomes, where signal was at least 2-fold higher in nrpel compared to Col-0 with an FDR of less than 0.05 [Figure S1A]. We validated a subset of Pol V stabilized nucleosomes by locus-specific MNase H3 ChIP-qPCR where we detected a significant decrease in nucleosome signal in nrpel compared to Col-0 wildtype at several tested loci [Figure 1E]. HSP70 was used as a negative control (Kumar and Wigge, 2010).

To test if Pol V stabilized and destabilized nucleosomes are located within Pol V-transcribed regions, we overlapped identified nucleosomes with previously published Pol V-transcribed regions (Böhmdorfer et al., 2016). Pol V stabilized nucleosomes showed a small overlap with annotated Pol Vtranscribed regions [Figure 1C], which was still significantly more than expected by chance [Figure 1D]. Consistently, the average level of Pol V transcription on Pol V stabilized nucleosomes was strongly enriched compared to adjacent regions or random sequences [Figure 1F]. Furthermore, like Pol V transcription, Pol V stabilized nucleosomes are enriched in intergenic and promoter regions [Figure S1DE]. On the other hand, overlaps between Pol V destabilized nucleosomes and annotated Pol V-transcribed regions were less likely than expected by chance [Figure S1B-C]. This indicates that Pol V stabilized nucleosomes are at least partially directly affected by Pol V and its downstream factors while Pol V destabilized nucleosome are most likely affected indirectly.

To determine if Pol V stabilized nucleosomes that do not overlap Pol V-transcribed regions may still be directly affected by Pol V, we measured their distance from Pol V transcribed regions. The 
average distance between Pol V stabilized nucleosomes and annotated Pol V-transcribed regions was significantly smaller than the average distance between random nucleosomes and annotated Pol Vtranscribed regions (Mann-Whitney test, p-value < 0.017) [Figure 1G]. This indicates that Pol V may directly affect nucleosomes that do not overlap annotated Pol V transcripts. Altogether, we conclude that Pol V stabilizes a pool of nucleosomes and at least a subset of those nucleosomes is likely to be directly affected by RdDM.

\section{Downstream RdDM components affect nucleosome positioning}

Involvement of Pol V in nucleosome positioning suggests that other components of the RdDM pathway may also be involved in this process. To test this prediction, we performed MNase-H3 ChIP followed by qPCR in Col-0 wildtype, nrpe1, ago4-1 and idn2-1 mutants. We detected a substantial decrease of the nucleosome signals in all three tested mutants compared to wildtype at Pol V stabilized nucleosomes [Figure 2A-G]. While nrpe1, as expected, affected all tested nucleosomes, ago 4 and idn2 had more locusspecific effects [Figure 2A-G]. This indicates that AGO4 and IDN2 both contribute to Pol V-mediated nucleosome positioning. This could be interpreted as evidence that events occurring downstream of Pol V transcription are involved in the observed changes in nucleosome positioning.

\section{Pol V-stabilized nucleosomes are enriched in repressive chromatin marks}

RdDM may affect nucleosome positioning in parallel with establishing repressive chromatin marks like DNA methylation and H3K9 dimethylation (H3K9me2). Alternatively, RdDM may establish nucleosomes and repressive chromatin marks on independent subsets of loci. To distinguish between those possibilities, we performed whole-genome bisulfite sequencing in Col-0 wildtype and nrpel in two biological replicates. We plotted DNA methylation levels in the CHH context at Pol V stabilized nucleosomes and $500 \mathrm{bp}$ adjacent regions [Figure 2H]. CHH DNA methylation was significantly enriched on Pol V stabilized nucleosomes compared to both the adjacent regions and the nrpel mutant [Figure $2 \mathrm{H}]$. To test if this enrichment is also dependent on AGO4 and IDN2, we used previously published whole-genome bisulfite sequencing datasets (Stroud et al., 2013). Likewise, we detected a reduction in the average DNA methylation levels in both ago4-1 and idn2-1 [Figure S2A]. These findings indicate that Pol V affects nucleosome positioning in parallel with establishing DNA methylation. This is consistent with genome-wide enrichment of DNA methylation on nucleosomes reported by Chodavarapu et al. (2010).

To determine if $\mathrm{H} 3 \mathrm{~K} 9 \mathrm{me} 2$ is also established in parallel, we performed MNase ChIP-qPCR using anti-H3K9me2 antibody in wildtype, nrpe1, ago4-1 and idn2-1 in three biological replicates. We used the anti-H3 antibody as a reference. The levels of $\mathrm{H} 3 \mathrm{~K} 9 \mathrm{me} 2$ relative to the levels of $\mathrm{H} 3$ were significantly 
reduced on tested Pol V stabilized nucleosomes in nrpel and ago4 [Figure 2K-L], unchanged on a negative control locus [Figure 2I] and reduced on a positive control locus [Figure 2J]. The idn2 mutant showed a locus-specific effect, which is consistent with demonstrated partial redundancy of IDN2 and its paralogs (Ausin et al., 2012; Xie et al., 2012). This indicates that at least at the tested loci Pol V affects nucleosome positioning in parallel with establishing H3K9me2. Together, these results indicate that $\mathrm{RdDM}$ affects nucleosome positioning in parallel with establishing repressive chromatin marks. This is consistent with a model where Pol V-stabilized nucleosomes are placed and modified by the RdDM pathway.

\section{Pol V positions nucleosomes via the SWI/SNF chromatin remodeling complex}

The presence of a physical interaction between an RdDM factor IDN2 and SWI3B, a subunit of the SWI/SNF chromatin remodeling complex (Zhu et al., 2013), indicates that Pol V may affect nucleosomes via the SWI/SNF complex. To test this possibility, we performed MNase H3 ChIP-seq in Col-0 wildtype and swi3b mutant. Although swi3b null mutants are embryo lethal (Sarnowski et al., 2005), we took advantage of the well documented observation that SWI3B is haploinsufficient (Sarnowski et al., 2002, 2005; Zhu et al., 2013) and used the swi3b/+ heterozygous plants. We plotted the average nucleosome signal at Pol V stabilized nucleosomes and adjacent regions [Figure 3A], compared to random nucleosomes identified in Col-0 wild type [Figure 3B]. Nucleosome signal at Pol V stabilized nucleosomes was reduced in swi3b/+ [Figure 3AC] but unchanged in adjacent regions [Figure 3AC] and at random nucleosomes [Figure 3BD]. Although the effect observed in swi3b/+ was statistically significant, it was much smaller than in nrpel [Figure 3A]. A significant but overall minor reduction in the nucleosomal signal in swi3b/+ was confirmed by locus-specific MNase H3 ChIP-qPCR, where we detected small but significant decreases in nucleosome signal in swi3b/+ compared to wildtype at tested loci [Figure S3A]. Partial reductions of nucleosome signals in swi3b/+ may be explained by the presence of one allele of $S W I 3 B$, other SWI3 paralogs and other chromatin remodeling complexes. Overall, these results indicate that the SWI/SNF complex only partially contributes to nucleosome positioning by RdDM.

\section{Preferential methylation of linker DNA}

Our observation that RdDM establishes both nucleosome positioning and repressive chromatin marks provides a possible explanation to prior observations that nucleosome positioning and DNA methylation are correlated (Chodavarapu et al., 2010; Lyons and Zilberman, 2017). However, prior studies in Arabidopsis used MNase digestion as the sole basis for the identification of nucleosomes (Chodavarapu et al., 2010; Lyons and Zilberman, 2017) and protections by DNA-binding proteins other than histones 
remain possible. To eliminate this possibility, we determined nucleosome positioning by MNase H3 ChIP-seq, which relies on MNase protection and binding of histone H3 to DNA to identify nucleosomes. We performed MNase H3 ChIP-seq and whole-genome bisulfite sequencing in two biological replicates of Col-0 wildtype. We first identified all nucleosome positions genome-wide $(n=650,610)$ and measured the average DNA methylation levels in all contexts (CG, $\mathrm{CHG}$ and $\mathrm{CHH})$ at nucleosomes and $500 \mathrm{bp}$ adjacent regions. We observed that DNA methylation was enriched on linker regions and depleted on nucleosomes in $\mathrm{CHG}$ and $\mathrm{CHH}$ sequence contexts [Figure 4B-D]. The CG methylation pattern was more complex, but linkers of neighboring nucleosomes showed strong enrichments in CG context [Figure 4A], which indicates that linkers are preferentially methylated in all sequence contexts. No enrichment was observed on matching random regions [Figure S4A-C]. This indicates that when nucleosomes are identified based on MNase protection and the presence of histone H3, linker regions are enriched in DNA methylation compared to regions occupied by nucleosomes. This correlation is apparent when analyzing all identified nucleosomes [Figure 4A-D] and in most subsets of nucleosomes present on specific genomic regions [Figure S4D-E].

Although the average levels of DNA methylation were higher on linker regions than on nucleosomes, a substantial subset of nucleosomes did not follow this general trend, including Pol V stabilized nucleosomes [Figure $2 \mathrm{H}$ ]. To determine if enrichment of DNA methylation on linkers is generally applicable, we focused on subsets of nucleosomes that show enrichment [Figure 4E] or depletion [Figure 4F] of CHH methylation on their linkers. We then used these subsets to test the enrichment of $\mathrm{CHH}$ methylation on linkers of neighboring nucleosomes, which are not expected to be biased by the selection of the central nucleosome. Nucleosomes that follow the general trend, showed the expected enrichment of $\mathrm{CHH}$ methylation on linkers of neighboring nucleosomes [Figure 4E]. Interestingly, nucleosomes filtered for depletion of $\mathrm{CHH}$ methylation on their linkers, still showed enrichment of $\mathrm{CHH}$ methylation on linkers of neighboring nucleosomes [Figure 4F]. This further confirms our observation that on average, DNA methylation is enriched on linker regions. We conclude that while Pol V stabilized nucleosomes are enriched in DNA methylation, the general genome-wide trend is preferential methylation of linker DNA.

\section{SWI/SNF complex is not required for DNA methylation on positioned nucleosomes}

The general trend of methylation depletion on nucleosomal DNA [Figure 4C] is not followed by Pol V stabilized nucleosomes, which are enriched in $\mathrm{CHH}$ methylation [Figure 2H]. This indicates that RdDM overrides general preferences of DNA methylation in respect to nucleosome positioning. This may be explained by a hypothesis that nucleosomes positioned by SWI/SNF are preferential substrates for DNA methyltransferases. To test this hypothesis, we assayed DNA methylation by whole-genome bisulfite 
sequencing in Col-0 wildtype and swi3b/+ in two biological replicates. We first analyzed $\mathrm{CHH}$ methylation levels on and around Pol V stabilized nucleosomes and observed no change in DNA methylation levels in swi3b/+ compared to Col-0 wild type [Figure 5A]. This indicates that the activity of SWI/SNF on Pol V-stabilized nucleosomes has no strong effect on DNA methylation.

To further test if nucleosomes positioned by SWI/SNF affect DNA methylation, we identified SWI3B stabilized nucleosomes, which are defined as nucleosomes that have a higher MNase H3 ChIPseq signal level in wildtype compared to $s w i 3 b /+$ with FDR of less than 0.05 . In total, we identified 4089 SWI3B stabilized nucleosomes, where the average nucleosome signal was significantly and reproducibly decreased in swi3b/+ [Figure S5A-B]. CHH methylation levels on SWI3B stabilized nucleosomes were not significantly changed in swi3b/+ compared to Col-0 wild type [Figure 5B, Figure S5C]. This indicates that changed patterns of nucleosome positioning in swi3b/+ do not affect the levels of $\mathrm{CHH}$ methylation. This suggests that nucleosomes positioned by the activity of SWI/SNF do not determine the pattern of DNA methylation.

\section{DNA methylation is needed for positioning nucleosomes at differentially methylated regions}

Our observation that correlations between nucleosomes and $\mathrm{CHH}$ methylation are not determined by nucleosome positioning suggests an alternative possibility that DNA methylation may participate in determining positions of nucleosomes. To test this prediction, we used previously published datasets (Stroud et al., 2013) to identify differentially methylated regions (DMRs), where CHH methylation is affected by DRM2. We then assayed nucleosome positioning by MNase H3 ChIP-seq in two biological replicates of Col-0 wildtype and drm2 mutant. At DRM2 DMRs, where lack of DRM2 resulted in strong reductions of $\mathrm{CHH}$ methylation [Figure 6A], the nucleosome signal was generally enriched in Col-0 wild type [Figure 6B]. This is consistent with Pol V stabilized nucleosomes being enriched in $\mathrm{CHH}$ methylation [Figure $2 \mathrm{H}$ ]. It is also in agreement with the observation that nucleosomes overlapping DRM2 DMRs behave like Pol V stabilized nucleosomes and are enriched in both CHH methylation and nucleosome signal [Figure S6A-B]. Importantly, in the drm2 mutant, DRM2 DMRs had a strong reduction in the nucleosome signal [Figure 6B]. This indicates that DNA methylation in the CHH context established by the RdDM pathway affects nucleosome positioning.

To test if this also applies to Pol V stabilized nucleosomes, we plotted the MNase H3 ChIP signal on Pol V stabilized nucleosomes in the drm 2 mutant compared to Col-0 wild type. Consistently with observations on DRM2 DMRs [Figure 6B] and nucleosomes overlapping DRM2 DMRs [Figure S6B], Pol V stabilized nucleosomes also had a reduction in nucleosome signal in the $d r m 2$ mutant [Figure S6C]. This further supports our observation that DNA methylation in the $\mathrm{CHH}$ context established by the RdDM pathway affects nucleosome positioning. 
To test if DNA methylation in CG and CHG contexts also affects nucleosome positioning we performed similar experiments and analysis in met 1 and cmt3 mutants. CG and CHG DMRs identified in $m e t 1$ and $c m t 3$, respectively, were enriched in the nucleosomal signal [Figure 6DF]. At MET1 DMRs, where lack of MET1 resulted in strong reductions of CG methylation [Figure 6C], the nucleosome signal was significantly reduced in met1 [Figure 6D]. Similarly, at CMT3 DMRs, where lack of CMT3 resulted in strong reductions of $\mathrm{CHG}$ methylation [Figure 6E], the nucleosome signal was also significantly reduced in $c m t 3$ [Figure $6 \mathrm{~F}$ ]. This indicates that DNA methylation affects nucleosome positioning irrespective of the sequence context.

\section{DISCUSSION}

We propose a model, where DNA methylation is a determinant of nucleosome positioning in RdDM. In this model, non-coding transcription by both Pol IV and Pol V leads to the recruitment of AGO4 and IDN2. IDN2 interacts with a subunit of SWI/SNF, which is however not sufficient to affect nucleosome positioning. Instead, the subsequent recruitment of DRM2 and establishment of DNA methylation activates chromatin remodelers and leads to changes in nucleosome positioning. Coordinated establishment of various chromatin marks leads to repression of Pol II promoters within the silenced region of the genome.

The effect of DNA methylation on nucleosome positioning may be explained by distinct intrinsic properties of DNA containing 5-methylcytosines, as suggested by (Collings et al., 2013). Alternatively, DNA methylation may facilitate the recruitment or activation of SWI/SNF, either directly or by the involvement of other proteins that are sensitive to the presence of 5-methylcytosines. Another possibility is that DNA methylation may affect nucleosome positioning by changing the pattern of posttranslational histone modifications. This includes $\mathrm{H} 3 \mathrm{~K} 9 \mathrm{me} 2$, which may recruit proteins that modulate the activity of chromatin remodelers. This also includes histone deacetylation, which may affect physical properties of the nucleosomes (Yang et al., 2020b; Zhang et al., 2018).

The importance of DNA methylation for nucleosome positioning has a significant impact on our understanding of the RdDM pathway. It argues against the pathway being branched after IDN2 recruitment (Zhu et al., 2013). Instead, it supports the notion that events occurring co-transcriptionally at the sites of Pol V transcription are organized in a stepwise genetic pathway (Böhmdorfer et al., 2014). Although when studied genetically, this pathway appears linear, various steps of the pathway are likely to rely on the cooperative recruitment or activation of subsequent factors. One example of such a connection is the requirement of both IDN2-SWI3B interaction and DNA methylation for nucleosome positioning. Other examples include the recruitment of AGO4, which has been proposed to rely on the interaction of AGO4 with NRPE1 C-terminal domain and with Pol V transcripts (El-Shami et al., 2007; Wierzbicki et 
al., 2009). Similarly, there is evidence of DRM2 being recruited by interactions with AGO4 and other RdDM factors (Gao et al., 2010; Zhong et al., 2014).

Our model is consistent with the notion that events in the late stages of RdDM lead to a concerted establishment of DNA methylation, posttranslational histone modifications and nucleosome positioning, which together form a repressive chromatin structure. This explains the robustness of transcriptional silencing, where coordinated establishment of various repressive chromatin marks leads to efficient repression of Pol II transcription. It is also consistent with the general difficulty to experimentally tease apart various repressive chromatin modifications established by this pathway.

The involvement of SWI/SNF and nucleosome positioning in RdDM may also be considered in the context of this pathway performing mostly maintenance of silencing. Transcription of heterochromatic regions by Pol IV and Pol V may involve the removal or repositioning of previously positioned nucleosomes. This is supported by the involvement of putative chromatin remodelers in initiation and/or elongation of transcription by both of those polymerases (Kanno et al., 2004; Smith et al., 2007; Wierzbicki et al., 2008; Zhou et al., 2018). Nucleosome positioning established as an outcome of RdDM may serve to re-create the pattern of nucleosomes disrupted by Pol IV and Pol V. De novo RdDM in newly inserted TEs is a distinct scenario, since no pre-existing repressive chromatin modifications are expected to exist. The role of nucleosome positioning in this de novo process remains unexplored.

The involvement of DNA methylation in determining the pattern of nucleosomes extends beyond RdDM targets. The impact of MET1-dependent CG methylation and CMT3-dependent CHG methylation on stabilizing nucleosomes indicates that DNA methylation may affect nucleosome patterns throughout the genome. This is consistent with findings in other eukaryotes (Collings and Anderson, 2017; Collings et al., 2013). Such a general effect of DNA methylation on nucleosome positioning would counteract the general preference to methylate linkers and contribute to local correlations between nucleosomes and DNA methylation. This property of nucleosomes is consistent with previous reports (Chodavarapu et al., 2010) and may involve the activity of DDM1 (Lyons and Zilberman, 2017). It illustrates the general interdependence between nucleosomes and DNA methylation.

Existing evidence does not support the view that DNA methylation is the primary determinant of the nucleosome pattern. This role remains reserved for a combination of intrinsic factors and active chromatin remodeling. The role of DNA methylation is more limited and probabilistic, clearly visible in meta-analysis of large pools of sequences. Therefore, opposite behaviors of individual loci are expected. Moreover, global losses of DNA methylation in RdDM and DNA methyltransferase mutants may affect the patterns of nucleosomes by a combination of cis- and trans-acting factors, which could only be distinguished using tools targeting DNA methylation to specific loci. 


\section{MATERIALS AND METHODS}

\section{Plant material}

Col-0 ecotype wildtype, nrpe1/nrpd1b-11 (Pontes et al., 2006), ago4-1 (introgressed into the Col-0 background (Wierzbicki et al., 2009)), idn2-1 (Ausin et al., 2009), drm2-2 (SAIL_70_E12, (Wierzbicki et al., 2008), swi3b-2 (GABI_302G08, (Sarnowski et al., 2005)), cmt3-11 (SALK_148381) and met1-3 (Saze et al., 2003) were grown at $22^{\circ} \mathrm{C}$ under white LED light in $16 \mathrm{~h} / 8 \mathrm{~h}$ day/night cycle.

\section{Antibodies}

Rabbit polyclonal anti-histone H3 antibody (ab1791) and mouse monoclonal anti-H3K9me2 antibody (ab1220) were obtained from Abcam.

\section{MNase H3 ChIP-seq}

2g of approximately 3.5-week old Arabidopsis thaliana mature leaf tissue, which was crosslinked with $0.5 \%$ formaldehyde, was ground in liquid nitrogen. MNase H3 ChIP of Col-0, met1, cmt 3 and drm 2 was carried out as described previously (Zhu et al., 2013). MNase H3 ChIP of Col-0, nrpel and swi3b was carried out using the following protocol. Cold nuclei isolation buffer I (10 mM Tris $\mathrm{HCl} \mathrm{pH} 8,10 \mathrm{mM}$ $\mathrm{MgCl}_{2}, 0.4 \mathrm{M}$ sucrose, $0.035 \% \beta$-mercaptoethanol, $1 \mathrm{mM}$ phenylmethylsulfonyl fluoride (PMSF)) was added. Tissue was resuspended by vigorous vortexing and shaking. Sample was filtered using Miracloth into new $50 \mathrm{ml}$ tube on ice. Miracloth was washed with $10 \mathrm{ml}$ of nuclei isolation buffer I. Sample was centrifuged $15 \mathrm{~min}, 4000 \mathrm{~g}, 4^{\circ} \mathrm{C}$.

Supernatant was discarded and nuclei pellet was resuspended using $1 \mathrm{ml}$ of cold nuclei isolation buffer II (10 mM Tris $\mathrm{HCl} \mathrm{pH} 8,10 \mathrm{mM} \mathrm{MgCl}_{2}, 0.4 \mathrm{M}$ sucrose, $1 \%$ Triton X-100, 0.035\% $\beta$ mercaptoethanol, 1mM phenylmethylsulfonyl fluoride (PMSF), 0.02 tab/ml cOmplete EDTA-free, 0.004 $\mathrm{mg} / \mathrm{ml}$ Pepstatin A). Sample was transferred to $1.5 \mathrm{ml}$ tube and centrifuged for $5 \mathrm{~min}, 2000 \mathrm{~g}, 4^{\circ} \mathrm{C}$. This step was repeated two more times. Pellet was resuspended using $300 \mu \mathrm{l}$ of cold Nuclei isolation buffer II and layered on top of cold $900 \mathrm{ml}$ Nuclei isolation buffer III ( $10 \mathrm{mM}$ Tris $\mathrm{HCl}$ pH8, $2 \mathrm{mM} \mathrm{MgCl} 2,1.7 \mathrm{M}$ sucrose, $0.15 \%$ Triton X-100, 0.035\% $\beta$-mercaptoethanol, $1 \mathrm{mM}$ phenylmethylsulfonyl fluoride (PMSF), $0.02 \mathrm{tab} / \mathrm{ml}$ cOmplete EDTA-free, $0.004 \mathrm{mg} / \mathrm{ml}$ Pepstatin A) in $1.5 \mathrm{ml}$ tube. Sample was centrifuged for $30 \mathrm{~min}, 16000 \mathrm{~g}, 4^{\circ} \mathrm{C}$ and supernatant was discarded.

Isolated nuclei were washed twice with Micrococcal Nuclease (MNase) reaction buffer (10 mM Tris $\mathrm{HCl} \mathrm{pH} 8,15 \mathrm{mM} \mathrm{NaCl}, 60 \mu \mathrm{M} \mathrm{KCl}, 1 \mathrm{mM} \mathrm{CaCl}_{2}$ ) and resuspended in the same buffer. MNase enzyme (NEB; 200 Kunitz unit/ $\mu$ l) was added and samples were mixed by vortexing. Samples were digested for 10 minutes at $30^{\circ} \mathrm{C} .1$ volume of MNase stop buffer $(30 \mathrm{mM}$ Tris $\mathrm{HCl} \mathrm{pH} 8,225 \mathrm{mM} \mathrm{NaCl}$, 
$10 \mathrm{mM}$ ethylenediaminetetraacetic acid (EDTA), $10 \mathrm{mM}$ egtazic acid (EGTA), 0.2\% sodium dodecyl sulphate (SDS), $2 \%$ Tween 20) was then added to stop the reaction. To release the chromatin from the nuclei, the sample was vortexed vigorously 5 times and centrifuged for $10 \mathrm{~min}, 14000 \mathrm{~g}$. The supernatant was then transferred to a new tube. Samples for H3 ChIP were then diluted in 1 volume ChIP dilution buffer (16.7 mM Tris $\mathrm{HCl} \mathrm{pH} 8,1.2 \mathrm{mM}$ ethylenediaminetetraacetic acid (EDTA), $167 \mathrm{mM} \mathrm{NaCl}, 1.1 \%$ Triton X-100, 1 mM phenylmethylsulfonyl fluoride (PMSF), 0.02 tab/ml cOmplete EDTA-free, 0.004 $\mathrm{mg} / \mathrm{ml}$ Pepstatin A). $\mathrm{H} 3$ antibody was added and sample was incubated $12-16$ hours, $4^{\circ} \mathrm{C}$ with rotation.

Protein A magnetic beads (Pierce ${ }^{\mathrm{TM}}$ ) were washed three times with IP buffer (50 mM HEPES pH7.5, $150 \mathrm{mM} \mathrm{NaCl}, 10 \mu \mathrm{M} \mathrm{ZnSO}_{4}, 1 \%$ Triton X-100, 0.05\% sodium dodecyl sulphate (SDS), $1 \mathrm{mM}$ phenylmethylsulfonyl fluoride (PMSF), $0.02 \mathrm{tab} / \mathrm{ml}$ cOmplete EDTA-free, $0.004 \mathrm{mg} / \mathrm{ml}$ Pepstatin A) and resuspended in $50 \mu \mathrm{IP}$ buffer. Beads were added to IP sample and incubated for 1 hour, $4^{\circ} \mathrm{C}$ with rotation. Immunoprecipitated chromatin bounded to magnetic beads was collected using magnetic separator. Beads were washed 5 min with cold buffers: two times with low salt buffer $(20 \mathrm{mM}$ Tris $\mathrm{HCl}$ pH8, 2 mM ethylenediaminetetraacetic acid (EDTA), $150 \mathrm{mM} \mathrm{NaCl}, 1 \%$ Triton $\mathrm{X}-100,0.1 \%$ sodium dodecyl sulphate (SDS)), once with high salt buffer (20 mM Tris $\mathrm{HCl}$ pH8, $2 \mathrm{mM}$ ethylenediaminetetraacetic acid (EDTA), $0.5 \mathrm{M} \mathrm{NaCl}, 1 \%$ Triton X-100, 0.1\% sodium dodecyl sulphate (SDS)), once with $\mathrm{LiCl}$ buffer (20 mM Tris $\mathrm{HCl} \mathrm{pH} 8,2 \mathrm{mM}$ ethylenediaminetetraacetic acid (EDTA), $250 \mathrm{mM} \mathrm{LiCl}, 1 \% \mathrm{NP}-100,1 \%$ sodium deoxycholate) ) and twice with TE buffer (10 mM Tris HCl pH8, 1 $\mathrm{mM}$ ethylenediaminetetraacetic acid (EDTA)). After the last wash, samples were transferred into new a tube and beads were collected using a magnetic separator.

For library preparation, magnetic beads were incubated with $100 \mu$ l Elution buffer $(10 \mathrm{mM}$ Tris $\mathrm{HCl} \mathrm{pH} 8,1 \mathrm{mM}$ ethylenediaminetetraacetic acid (EDTA), 1\% sodium dodecyl sulphate (SDS)) in a thermomixer $\left(65^{\circ} \mathrm{C}, 1400 \mathrm{rpm}, 30 \mathrm{~min}\right)$. Beads were collected using magnetic separator and supernatant was transferred into new tube. Step was repeated and both supernatants combined. IP samples were decrosslinked by Proteinase $\mathrm{K}$ treatment $\left(5 \mu 1,65^{\circ} \mathrm{C}, 12 \mathrm{~h}\right)$. Samples were purified using QIAquick ${ }^{\circledR}$ PCR Purification Kit (35 $\mu$ l of EB buffer were used). Library for Illumina sequencing was prepared using either MicroPlex Library Preparation ${ }^{\mathrm{TM}}$ Kit (Diagenode) according manufacturer instruction, using inhouse library preparation based on Bowman et al (Bowman et al., 2013), or prepared by the University of Michigan Advanced Genomics Core. MNase ChIP-seq experiments were performed in two biological replicates and sequenced by either $50 \mathrm{bp}$ or $150 \mathrm{bp}$ paired-end sequencing at the University of Michigan Advanced Genomics Core.

\section{MNase H3 \& H3K9me2 ChIP-qPCR}


Nuclei were extracted from 2g of approximately 3.5-week old Arabidopsis thaliana mature leaf tissue which was crosslinked with formaldehyde [0.5\%] as described previously(Zhu et al., 2013) and were digested with Micrococcal Nuclease (MNase ; NEB) for 10 minutes at $30^{\circ} \mathrm{C}$. MNase-digested chromatin was immunoprecipitated with anti-histone $\mathrm{H} 3$ antibody or anti-H3K9me2 antibody. DNA was purified and used for qPCR analysis. MNase ChIP-qPCR experiments were performed in three biological replicates with region-specific primers listed in Supplementary table 1.

\section{Whole genome bisulfite-seq}

Genomic DNA was isolated from approximately 3.5-week old Arabidopsis thaliana mature leaf tissue of Col-0 wild type, swi3b/+ and nrpel using DNeasy Plant Mini Kit (QIAGEN). DNA was processed for bisulfite treatment and library generation at the University of Michigan Advanced Genomics Core.

\section{Bioinformatic data analysis}

MNase H3 ChIP-seq paired-end reads from two independent biological replicates were aligned and processed to the Arabidopsis TAIR10 genome with Bowtie2 (Langmead and Salzberg, 2012). Mapped reads were deduplicated using PICARD tools (http://broadinstitute.github.io/picard) and filtered by fragment length between 120-170 bp and MAPQ value of $>=2$. Differential nucleosomes were identified using DANPOS2 (Chen et al., 2013) by filtering nucleosomes with more than 2 fold enrichment in either in Col-0 for PolV stabilized nucleosomes or in nrpel for PolV destabilized nucleosomes and FDR $<0.05$. Nucleosomes are then filtered using the negative binomial test with reads from biological replicates using the NBPseq R package (Di et al., 2011). For subsequent analysis we selected nucleosomes which showed more than 2 fold-change and FDR $<0.05$. We further refined the nucleosome positions for wellpositioned nucleosomes by filtering for main peak nucleosomes using iNPS (Chen et al., 2014). Nucleosome data was (RPM) normalized and visualized on heatmaps and profiles by calculating the number of reads using BEDTools 2.15.0 at nucleosome dyads (Quinlan and Hall, 2010). Overlap analyses with nucleosomes were performed with 1000 permutated genomic regions to obtain expected numbers and $\mathrm{p}$ values. SWI3B-stabilized nucleosomes were filtered for higher read counts in Col-0 than the $s w i 3 b$ mutant and an FDR $<0.05$. These nucleosomes were then further filtered using the negative binomial test with reads from biological duplicates using NBPseq and the nucleosomes with FDR $<0.01$ were selected for further analysis.

Hypermethylated nucleosomes were identified by filtering for nucleosomes with higher DNA methylation level in CHH-context inside the nucleosomes (140bps), compared to their adjacent DNA linker regions (30bps upstream and downstream of nucleosomes). The nucleosomes were filtered for the presence of more than $8 \mathrm{CHH}$-context cytosines within the nucleosomes and more than $2 \mathrm{CHH}$-context 
Cs in each of the adjacent linkers to correct for the sizes of the regions and frequencies of Cs.

Hypomethylated nucleosomes were similarly identified, except these regions had higher levels of CHHcontext DNA methylation in the adjacent DNA linker regions than the nucleosomes.

The sequencing reads from whole genome bisulfite-seq datasets were mapped to the TAIR10 genome using the Bismark software allowing no mismatches (Krueger and Andrews, 2011). DNA methylation levels were calculated by the ratio of $\# \mathrm{C} /(\# \mathrm{C}+\# \mathrm{~T})$ after selecting for $\mathrm{Cs}$ with at least 5 sequenced reads. Differentially Methylated Regions (DMRs) were identified using methylKit package in $\mathrm{R}$ (Akalin et al., 2012). The bin sizes used were 100bp bins with a step-size of 50bps. 10 minimum bases were required in each tile. A $10 \%$ minimum methylation difference was selected for in each of the tiles and an FDR value of 0.01 was used. The number of MNase-H3 ChIP-seq reads overlapping these DMRs were then plotted as a profile.

\section{Other datasets used in this study}

Arabidopsis genome annotations (TAIR10) were obtained from TAIR (www.arabidopsis.org). Pol V ChIP-seq data (SRA054962) and peak list and Pol V RIP-seq data (GSE70290) and annotated regions were published previously (Böhmdorfer et al., 2016; Wierzbicki et al., 2012). DNA methylation data from idn2, ago4, drm 2, met 1 and cmt3 mutants as well as corresponding Col-0 and nrpel controls were obtained from GSE39901 (Stroud et al., 2013).

\section{Data deposition}

High throughput sequencing datasets obtained in this study have been deposited in Gene Expression Omnibus under accession GSE148173.

\section{ACKNOWLEDGMENTS}

Research reported in this publication was supported by the National Institute of General Medical Sciences of the National Institutes of Health under award number R01GM108722 to ATW. JD was supported by the National Science Center grants Etiuda UMO-2014/12/T/NZ2/00246 and Opus UMO-

2017/25/B/NZ1/00603.

\section{FIGURE LEGENDS}

Figure 1: Pol V affects nucleosomes by a combination of direct and indirect mechanisms.

A. Genome browser screenshot showing a Pol V stabilized nucleosome.

B. Comparison of MNase H3 ChIP-seq signal in Col-0 and nrpel on Pol V stabilized nucleosomes. 
C. Locus-specific validation of Pol V stabilized nucleosomes. Significance tested using t-test (n.s. $=$ not significant, $* *=\mathrm{p}$ - value $<0.01, * * *=\mathrm{p}$-value $<0.001)$. ChIP signal values were normalized to ACTIN2 and Col-0 wild-type. Error bars show standard deviations from three biological replicates.

D. Overlap between Pol V stabilized nucleosomes and annotated Pol V transcribed regions.

E. Enrichment of Pol V stabilized nucleosomes on annotated Pol V transcribed or bound regions (random permutation test; 1000 iterations; p-value $<0.001$ ).

F. Pol V RNA immunoprecipitation signal on Pol V stabilized nucleosomes and random nucleosomes. The nucleosomal regions are indicated with vertical dashed lines.

G. Distance of Pol V stabilized nucleosomes or random nucleosomes to annotated Pol V transcribed regions.

Figure 2: IDN2 connects siRNA and lncRNA to nucleosome positioning.

A. - G. Locus-specific analysis of MNase H3-ChIP qPCR levels on Pol V stabilized nucleosomes in Col-0, nrpe1, ago4-1 and idn2-1. Significance tested using t-test (n.s. = not significant, $* *=\mathrm{p}$ value $<0.01, * * *=p$-value $<0.001)$. ChIP signal values were normalized to ACTIN2 and Col-0 wild-type. Error bars show standard deviations from three biological replicates.

H. Average profile of DNA methylation levels (CHH context) on Pol V stabilized nucleosome dyads.

I. - K. Locus-specific analysis of H3K9me2 levels in ACTIN2, IGN22 and Pol V stabilized nucleosomes in Col-0, nrpe1, ago4 and idn2-1. Significance tested using t-test (n.s. = not significant, $*=$ p-value $<0.05, * *=$ p-value $<0.01, * * *=$ p-value $<0.001)$. H3K9me2 ChIP signal values were normalized to $\mathrm{H} 3$ and Col-0 wild-type. Error bars show standard deviations from three biological replicates.

Figure 3: Pol V positions nucleosomes through the SWI/SNF complex.

A. Average levels of MNase H3 ChIP-seq signal on Pol V stabilized nucleosomes in Col-0, nrpe1 and swi3b/+. Ribbons indicate confidence intervals with $\mathrm{p}<0.05$.

B. Average levels of MNase H3 ChIP-seq signal on random nucleosomes in Col-0, nrpel and swi3b/+. Ribbons indicate confidence intervals with $\mathrm{p}<0.05$.

C. Heatmap of levels of MNase H3 ChIP-seq signal on Pol V stabilized nucleosomes in Col-0, nrpe 1 and $s w i 3 b /+$.

D. Heatmap of levels of MNase H3 ChIP-seq signal on random nucleosomes in Col-0, nrpel and swi3b/+.

Figure 4: Preferential methylation of linker DNA 
A. - C. Average CG (A), CHG (B) and CHH (C) methylation levels on and around all annotated nucleosomes. Dark grey shading indicates the annotated nucleosome and four neighboring nucleosomes. Ribbon indicates confidence intervals with $\mathrm{p}<0.05$.

D. Average MNase H3 ChIP signal levels at and around annotated nucleosomes (X axis) by sequenced fragment length (y axis).

E. Average levels of $\mathrm{CHH}$ methylation around hypomethylated nucleosomes. Dark grey shading indicates the annotated nucleosome and four neighboring nucleosomes. Ribbon indicates confidence intervals with $\mathrm{p}<0.05$. Scatterplot below shows average MNase H3 ChIP signal levels at and around hypomethylated nucleosomes ( $\mathrm{X}$ axis) by sequenced fragment length ( $\mathrm{y}$ axis).

F. Average levels of $\mathrm{CHH}$ methylation around hypermethylated nucleosomes. Dark grey shading indicates the annotated nucleosome and four neighboring nucleosomes. Ribbon indicates confidence intervals with $\mathrm{p}<0.05$. Scatterplot below shows average MNase H3 ChIP signal levels at and around hypermethylated nucleosomes ( $\mathrm{X}$ axis) by sequenced fragment length ( $\mathrm{y}$ axis).

Figure 5: SWI/SNF complex is not required for DNA methylation on positioned nucleosomes.

A. Average levels of $\mathrm{CHH}$ methylation on and around Pol V stabilized nucleosomes. X axis indicates position (bp). Ribbons indicate confidence intervals with $\mathrm{p}<0.05$.

B. Average levels of $\mathrm{CHH}$ methylation on and around SWI3B stabilized nucleosomes. X axis indicates position (bp). Ribbons indicate confidence intervals with $\mathrm{p}<0.05$.

Figure 6: DNA methylation is needed for positioning nucleosomes at differentially methylated regions.

A. Average levels of $\mathrm{CHH}$ methylation at and around regions that lose $\mathrm{CHH}$ methylation in the drm2 mutant (DRM2 DMRs). Ribbons indicate confidence intervals with $\mathrm{p}<0.05$.

B. Average levels of MNase H3 ChIP signal at and around DRM2 DMRs. Ribbons indicate confidence intervals with $\mathrm{p}<0.05$.

C. Average levels of CG methylation at and around regions that lose CG methylation in the met 1 mutant (MET1 DMRs). Ribbons indicate confidence intervals with $\mathrm{p}<0.05$.

D. Average levels of MNase H3 ChIP signal at and around MET1 DMRs. Ribbons indicate confidence intervals with $\mathrm{p}<0.05$.

E. Average levels of CHG methylation at and around regions that lose $\mathrm{CHG}$ methylation in the $\mathrm{cmt} 3$ mutant (CMT3 DMRs). Ribbons indicate confidence intervals with $\mathrm{p}<0.05$.

F. Average levels of MNase H3 ChIP signal at and around CMT3 DMRs. Ribbons indicate confidence intervals with $\mathrm{p}<0.05$. 


\section{SUPPLEMENTAL FIGURE LEGENDS}

Table S1: Oligonucleotides used in this study.

Figure S1: Pol V affects nucleosomes by a combination of direct and indirect mechanisms.

A. MNase H3-ChIP seq signal on Pol V destabilized nucleosomes.

B. Overlap between Pol V destabilized nucleosomes and annotated Pol V transcribed regions.

C. Enrichment of Pol V destabilized nucleosomes on annotated Pol V transcribed or bound regions (random permutation test; 1000 iterations; p-value $<0.001$ ).

D. Enrichment of Pol V stabilized nucleosomes on various genomic regions (random permutation test; 1000 iterations; $p$-value $<0.001)$.

E. Enrichment of Pol V stabilized nucleosomes on annotated transposable element regions (random permutation test; 1000 iterations; p-value $<0.001$ ).

Figure S2: IDN2 connects siRNA and lncRNA to nucleosome positioning.

A. Average levels of $\mathrm{CHH}$ methylation on and around Pol V stabilized nucleosomes dyads using datasets from Stroud et al (2013).

Figure S3: Pol V positions nucleosomes through the SWI/SNF complex.

A. Locus-specific validation of Pol V stabilized nucleosomes by MNase H3 ChIP followed by qPCR. Significance tested using t-test (n.s. $=$ not significant, $*=$ p-value $<0.05, * *=$ p-value $<$ $0.01,{ }^{* * *}=\mathrm{p}$-value $\left.<0.001\right)$. ChIP signal values were normalized to ACTIN2 and Col-0 wildtype. Error bars indicate standard deviations from three biological replicates.

Figure S4: Preferential methylation of linker DNA.

A. Average levels of CG methylation at random nucleosome-sized regions. Ribbon indicates confidence intervals with $\mathrm{p}<0.05$.

B. Average levels of CHG methylation at random nucleosome-sized regions. Ribbon indicates confidence intervals with $\mathrm{p}<0.05$.

C. Average levels of $\mathrm{CHH}$ methylation at random nucleosome-sized regions. Ribbon indicates confidence intervals with $\mathrm{p}<0.05$.

D. Average levels of $\mathrm{CG}, \mathrm{CHG}$ and $\mathrm{CHH}$ methylation at and around annotated nucleosomes overlapping exons or introns.

E. Average levels of $\mathrm{CG}, \mathrm{CHG}$ and $\mathrm{CHH}$ methylation at and around annotated nucleosomes overlapping gene bodies, TSS, intergenic regions and transposable elements.

Figure S5: SWI/SNF complex is not required for DNA methylation on positioned nucleosomes.

A. Average levels of MNase $\mathrm{H} 3 \mathrm{ChIP}$ in two biological replicates of Col-0, nrpel and swi3b/+ at and around SWI3B stabilized nucleosomes. 
B. Comparison of biological replicates of MNase H3 ChIP in Col-0 and swi3b/+. Colors scale represents FDR cutoff values.

C. DNA methylation levels at individual SWI3B stabilized nucleosomes.

Figure S6: DNA methylation is needed for positioning nucleosomes at differentially methylated regions.

A. Average levels of $\mathrm{CHH}$ methylation at and around annotated nucleosomes that overlap DRM2 DMRs. Ribbons indicate confidence intervals with $\mathrm{p}<0.05$.

B. Average levels of MNase H3 ChIP signal at nucleosomes overlapping DRM2 DMRs. Ribbons indicate confidence intervals with $\mathrm{p}<0.05$.

C. Average levels of MNase H3 ChIP signal at Pol V stabilized nucleosomes. Ribbons indicate confidence intervals with $\mathrm{p}<0.05$.

\section{REFERENCES}

Akalin, A., Kormaksson, M., Li, S., Garrett-Bakelman, F.E., Figueroa, M.E., Melnick, A., and Mason, C.E. (2012). methylKit: a comprehensive R package for the analysis of genome-wide DNA methylation profiles. Genome Biology 13, R87.

Archacki, R., Yatusevich, R., Buszewicz, D., Krzyczmonik, K., Patryn, J., Iwanicka-Nowicka, R., Biecek, P., Wilczynski, B., Koblowska, M., Jerzmanowski, A., et al. (2017). Arabidopsis SWI/SNF chromatin remodeling complex binds both promoters and terminators to regulate gene expression. Nucleic Acids Res 45, 3116-3129.

Ausin, I., Mockler, T.C., Chory, J., and Jacobsen, S.E. (2009). IDN1 and IDN2 are required for de novo DNA methylation in Arabidopsis thaliana. Nature Structural \& Molecular Biology 16, 1325.

Ausin, I., Greenberg, M.V.C., Simanshu, D.K., Hale, C.J., Vashisht, A.A., Simon, S.A., Lee, T., Feng, S., Española, S.D., Meyers, B.C., et al. (2012). INVOLVED IN DE NOVO 2-containing complex involved in RNA-directed DNA methylation in Arabidopsis. PNAS 109, 8374-8381.

Blevins, T., Podicheti, R., Mishra, V., Marasco, M., Wang, J., Rusch, D., Tang, H., and Pikaard, C.S. (2015). Identification of Pol IV and RDR2-dependent precursors of $24 \mathrm{nt}$ siRNAs guiding de novo DNA methylation in Arabidopsis. ELife Sciences 4, e09591.

Böhmdorfer, G., Rowley, M.J., Kuciński, J., Zhu, Y., Amies, I., and Wierzbicki, A.T. (2014). RNAdirected DNA methylation requires stepwise binding of silencing factors to long non-coding RNA. Plant J 79, 181-191.

Böhmdorfer, G., Sethuraman, S., Rowley, M.J., Krzyszton, M., Rothi, M.H., Bouzit, L., and Wierzbicki, A.T. (2016). Long non-coding RNA produced by RNA polymerase V determines boundaries of heterochromatin. ELife Sciences 5, e19092. 
Bowman, S.K., Simon, M.D., Deaton, A.M., Tolstorukov, M., Borowsky, M.L., and Kingston, R.E. (2013). Multiplexed Illumina sequencing libraries from picogram quantities of DNA. BMC Genomics 14, 466.

Brzeski, J., Podstolski, W., Olczak, K., and Jerzmanowski, A. (1999). Identification and analysis of the Arabidopsis thaliana BSH gene, a member of the SNF5 gene family. Nucleic Acids Res 27, 2393-2399.

Cao, X., and Jacobsen, S.E. (2002). Role of the Arabidopsis DRM Methyltransferases in De Novo DNA Methylation and Gene Silencing. Current Biology 12, 1138-1144.

Chen, K., Xi, Y., Pan, X., Li, Z., Kaestner, K., Tyler, J., Dent, S., He, X., and Li, W. (2013). DANPOS: dynamic analysis of nucleosome position and occupancy by sequencing. Genome Res. 23, 341-351.

Chen, W., Liu, Y., Zhu, S., Green, C.D., Wei, G., and Han, J.-D.J. (2014). Improved nucleosomepositioning algorithm iNPS for accurate nucleosome positioning from sequencing data. Nat Commun 5 , $1-14$.

Chodavarapu, R.K., Feng, S., Bernatavichute, Y.V., Chen, P.-Y., Stroud, H., Yu, Y., Hetzel, J.A., Kuo, F., Kim, J., Cokus, S.J., et al. (2010). Relationship between nucleosome positioning and DNA methylation. Nature 466, 388 .

Collings, C.K., and Anderson, J.N. (2017). Links between DNA methylation and nucleosome occupancy in the human genome. Epigenetics \& Chromatin 10, 18.

Collings, C.K., Waddell, P.J., and Anderson, J.N. (2013). Effects of DNA methylation on nucleosome stability. Nucleic Acids Res 41, 2918-2931.

Di, Y., Schafer, D.W., Cumbie, J.S., and Chang, J.H. (2011). The NBP Negative Binomial Model for Assessing Differential Gene Expression from RNA-Seq. Statistical Applications in Genetics and Molecular Biology 10.

Du, J., Johnson, L.M., Jacobsen, S.E., and Patel, D.J. (2015). DNA methylation pathways and their crosstalk with histone methylation. Nature Reviews Molecular Cell Biology 16, 519.

El-Shami, M., Pontier, D., Lahmy, S., Braun, L., Picart, C., Vega, D., Hakimi, M.-A., Jacobsen, S.E., Cooke, R., and Lagrange, T. (2007). Reiterated WG/GW motifs form functionally and evolutionarily conserved ARGONAUTE-binding platforms in RNAi-related components. Genes Dev. 21, 2539-2544.

Felle, M., Hoffmeister, H., Rothammer, J., Fuchs, A., Exler, J.H., and Längst, G. (2011). Nucleosomes protect DNA from DNA methylation in vivo and in vitro. Nucleic Acids Res 39, 6956-6969.

Gao, Z., Liu, H.-L., Daxinger, L., Pontes, O., He, X., Qian, W., Lin, H., Xie, M., Lorkovic, Z.J., Zhang, S., et al. (2010). An RNA polymerase II- and AGO4-associated protein acts in RNA-directed DNA methylation. Nature 465, 106-109.

Han, S.-K., Sang, Y., Rodrigues, A., F2010, B., Wu, M.-F., Rodriguez, P.L., and Wagner, D. (2012). The SWI2/SNF2 Chromatin Remodeling ATPase BRAHMA Represses Abscisic Acid Responses in the Absence of the Stress Stimulus in Arabidopsis. The Plant Cell 24, 4892-4906. 
Huff, J.T., and Zilberman, D. (2014). Dnmt1-independent CG methylation contributes to nucleosome positioning in diverse eukaryotes. Cell 156, 1286-1297.

Johnson, L.M., Du, J., Hale, C.J., Bischof, S., Feng, S., Chodavarapu, R.K., Zhong, X., Marson, G., Pellegrini, M., Segal, D.J., et al. (2014). SRA- and SET-domain-containing proteins link RNA polymerase V occupancy to DNA methylation. Nature 507, 124.

Kanno, T., Mette, M.F., Kreil, D.P., Aufsatz, W., Matzke, M., and Matzke, A.J.M. (2004). Involvement of Putative SNF2 Chromatin Remodeling Protein DRD1 in RNA-Directed DNA Methylation. Current Biology 14, 801-805.

Krueger, F., and Andrews, S.R. (2011). Bismark: a flexible aligner and methylation caller for BisulfiteSeq applications. Bioinformatics 27, 1571-1572.

Kumar, S.V., and Wigge, P.A. (2010). H2A.Z-Containing Nucleosomes Mediate the Thermosensory Response in Arabidopsis. Cell 140, 136-147.

Lahmy, S., Pontier, D., Bies-Etheve, N., Laudié, M., Feng, S., Jobet, E., Hale, C.J., Cooke, R., Hakimi, M.-A., Angelov, D., et al. (2016). Evidence for ARGONAUTE4-DNA interactions in RNA-directed DNA methylation in plants. Genes Dev. 30, 2565-2570.

Langmead, B., and Salzberg, S.L. (2012). Fast gapped-read alignment with Bowtie 2. Nat Methods 9, $357-359$.

Law, J.A., Du, J., Hale, C.J., Feng, S., Krajewski, K., Palanca, A.M.S., Strahl, B.D., Patel, D.J., and Jacobsen, S.E. (2013). Polymerase IV occupancy at RNA-directed DNA methylation sites requires SHH1. Nature 498, 385.

Li, C., Gu, L., Gao, L., Chen, C., Wei, C.-Q., Qiu, Q., Chien, C.-W., Wang, S., Jiang, L., Ai, L.-F., et al. (2016). Concerted genomic targeting of H3K27 demethylase REF6 and chromatin-remodeling ATPase BRM in Arabidopsis. Nature Genetics 48, 687.

Liu, Z.-W., Zhou, J.-X., Huang, H.-W., Li, Y.-Q., Shao, C.-R., Li, L., Cai, T., Chen, S., and He, X.-J. (2016). Two Components of the RNA-Directed DNA Methylation Pathway Associate with MORC6 and Silence Loci Targeted by MORC6 in Arabidopsis. PLOS Genetics 12, e1006026.

Lyons, D.B., and Zilberman, D. (2017). DDM1 and Lsh remodelers allow methylation of DNA wrapped in nucleosomes. ELife Sciences 6, e30674.

Matzke, M.A., and Mosher, R.A. (2014). RNA-directed DNA methylation: an epigenetic pathway of increasing complexity. Nature Reviews Genetics 15, 394.

Mette, M.F., Winden, J. van der, Matzke, M.A., and Matzke, A.J.M. (1999). Production of aberrant promoter transcripts contributes to methylation and silencing of unlinked homologous promoters in trans. The EMBO Journal 18, 241-248.

Mette, M.F., Aufsatz, W., Winden, J. van der, Matzke, M.A., and Matzke, A.J.M. (2000). Transcriptional silencing and promoter methylation triggered by double-stranded RNA. The EMBO Journal 19, 51945201. 
Pontes, O., Li, C.F., Nunes, P.C., Haag, J., Ream, T., Vitins, A., Jacobsen, S.E., and Pikaard, C.S. (2006). The Arabidopsis Chromatin-Modifying Nuclear siRNA Pathway Involves a Nucleolar RNA Processing Center. Cell 126, 79-92.

Quinlan, A.R., and Hall, I.M. (2010). BEDTools: a flexible suite of utilities for comparing genomic features. Bioinformatics 26, 841-842.

Sacharowski, S.P., Gratkowska, D.M., Sarnowska, E.A., Kondrak, P., Jancewicz, I., Porri, A., Bucior, E., Rolicka, A.T., Franzen, R., Kowalczyk, J., et al. (2015). SWP73 Subunits of Arabidopsis SWI/SNF Chromatin Remodeling Complexes Play Distinct Roles in Leaf and Flower Development. The Plant Cell 27, 1889-1906.

Sarnowski, T.J., Świeżewski, S., Pawlikowska, K., Kaczanowski, S., and Jerzmanowski, A. (2002). AtSWI3B, an Arabidopsis homolog of SWI3, a core subunit of yeast Swi/Snf chromatin remodeling complex, interacts with FCA, a regulator of flowering time. Nucleic Acids Res 30, 3412-3421.

Sarnowski, T.J., Ríos, G., Jásik, J., Świeżewski, S., Kaczanowski, S., Li, Y., Kwiatkowska, A., Pawlikowska, K., Koźbiał, M., Koźbiał, P., et al. (2005). SWI3 Subunits of Putative SWI/SNF Chromatin-Remodeling Complexes Play Distinct Roles during Arabidopsis Development. The Plant Cell $17,2454-2472$.

Saze, H., Scheid, O.M., and Paszkowski, J. (2003). Maintenance of CpG methylation is essential for epigenetic inheritance during plant gametogenesis. Nature Genetics 34, 65-69.

Smith, L.M., Pontes, O., Searle, I., Yelina, N., Yousafzai, F.K., Herr, A.J., Pikaard, C.S., and Baulcombe, D.C. (2007). An SNF2 protein associated with nuclear RNA silencing and the spread of a silencing signal between cells in Arabidopsis. Plant Cell 19, 1507-1521.

Stroud, H., Greenberg, M.V.C., Feng, S., Bernatavichute, Y.V., and Jacobsen, S.E. (2013).

Comprehensive Analysis of Silencing Mutants Reveals Complex Regulation of the Arabidopsis Methylome. Cell 152, 352-364.

Stroud, H., Do, T., Du, J., Zhong, X., Feng, S., Johnson, L., Patel, D.J., and Jacobsen, S.E. (2014). NonCG methylation patterns shape the epigenetic landscape in Arabidopsis. Nature Structural \& Molecular Biology 21, 64.

Wagner, D., and Meyerowitz, E.M. (2002). SPLAYED, a Novel SWI/SNF ATPase Homolog, Controls Reproductive Development in Arabidopsis. Current Biology 12, 85-94.

Wierzbicki, A.T., Haag, J.R., and Pikaard, C.S. (2008). Noncoding Transcription by RNA Polymerase Pol $\mathrm{IVb} / \mathrm{Pol} \mathrm{V}$ Mediates Transcriptional Silencing of Overlapping and Adjacent Genes. Cell 135, 635-648.

Wierzbicki, A.T., Ream, T.S., Haag, J.R., and Pikaard, C.S. (2009). RNA polymerase V transcription guides ARGONAUTE4 to chromatin. Nature Genetics 41, 630.

Wierzbicki, A.T., Cocklin, R., Mayampurath, A., Lister, R., Rowley, M.J., Gregory, B.D., Ecker, J.R., Tang, H., and Pikaard, C.S. (2012). Spatial and functional relationships among Pol V-associated loci, Pol IV-dependent siRNAs, and cytosine methylation in the Arabidopsis epigenome. Genes Dev. 26, 18251836. 
Xie, M., Ren, G., Zhang, C., and Yu, B. (2012). The DNA- and RNA-binding protein FACTOR of DNA METHYLATION 1 requires XH domain-mediated complex formation for its function in RNA-directed DNA methylation. Plant J. 72, 491-500.

Yang, J., Yuan, L., Yen, M.-R., Zheng, F., Ji, R., Peng, T., Gu, D., Yang, S., Cui, Y., Chen, P.-Y., et al. (2020a). SWI3B and HDA6 interact and are required for transposon silencing in Arabidopsis. The Plant Journal 102, 809-822.

Yang, J., Yuan, L., Yen, M.-R., Zheng, F., Ji, R., Peng, T., Gu, D., Yang, S., Cui, Y., Chen, P.-Y., et al. (2020b). SWI3B and HDA6 interact and are required for transposon silencing in Arabidopsis. The Plant Journal 102, 809-822.

Ye, R., Wang, W., Iki, T., Liu, C., Wu, Y., Ishikawa, M., Zhou, X., and Qi, Y. (2012). Cytoplasmic Assembly and Selective Nuclear Import of Arabidopsis ARGONAUTE4/siRNA Complexes. Molecular Cell 46, 859-870.

Zemach, A., Kim, M.Y., Hsieh, P.-H., Coleman-Derr, D., Eshed-Williams, L., Thao, K., Harmer, S.L., and Zilberman, D. (2013). The Arabidopsis Nucleosome Remodeler DDM1 Allows DNA Methyltransferases to Access H1-Containing Heterochromatin. Cell 153, 193-205.

Zhai, J., Bischof, S., Wang, H., Feng, S., Lee, T., Teng, C., Chen, X., Park, S.Y., Liu, L., GallegoBartolome, J., et al. (2015). A One Precursor One siRNA Model for Pol IV-Dependent siRNA Biogenesis. Cell 163, 445-455.

Zhang, C., Du, X., Tang, K., Yang, Z., Pan, L., Zhu, P., Luo, J., Jiang, Y., Zhang, H., Wan, H., et al. (2018). Arabidopsis AGDP1 links H3K9me2 to DNA methylation in heterochromatin. Nature Communications 9, 4547.

Zhong, X., Du, J., Hale, C.J., Gallego-Bartolome, J., Feng, S., Vashisht, A.A., Chory, J., Wohlschlegel, J.A., Patel, D.J., and Jacobsen, S.E. (2014). Molecular mechanism of action of plant DRM de novo DNA methyltransferases. Cell 157, 1050-1060.

Zhou, M., Palanca, A.M.S., and Law, J.A. (2018). Locus-specific control of the de novo DNA methylation pathway in Arabidopsis by the CLASSY family. Nat. Genet. 50, 865-873.

Zhu, Y., Rowley, M.J., Böhmdorfer, G., and Wierzbicki, A.T. (2013). A SWI/SNF ChromatinRemodeling Complex Acts in Noncoding RNA-Mediated Transcriptional Silencing. Molecular Cell 49, 298-309.

Zilberman, D., Cao, X., and Jacobsen, S.E. (2003). ARGONAUTE4 Control of Locus-Specific siRNA Accumulation and DNA and Histone Methylation. Science 299, 716-719. 
bioRxiv preprint doi: https://doi.org/10.1101/2020.10.29.359794; this version posted October 29, 2020. The copyright holder for this preprint (which was not certified by peer review) is the author/funder, who has granted bioRxiv a license to display the preprint in perpetuity. It is made

A

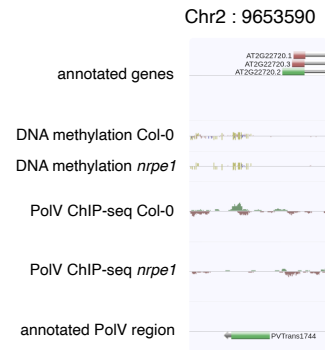

MNase Histone 3 ChIP-seq Col-0 replicate 1

MNase Histone 3 ChIP-seq nrpe1 replicate 1

MNase Histone 3 ChIP-seq Col-0 replicate 2

MNase Histone 3 ChIP-seq nrpe1 replicate 2

Identified PolV stabilized nucleosomes

C

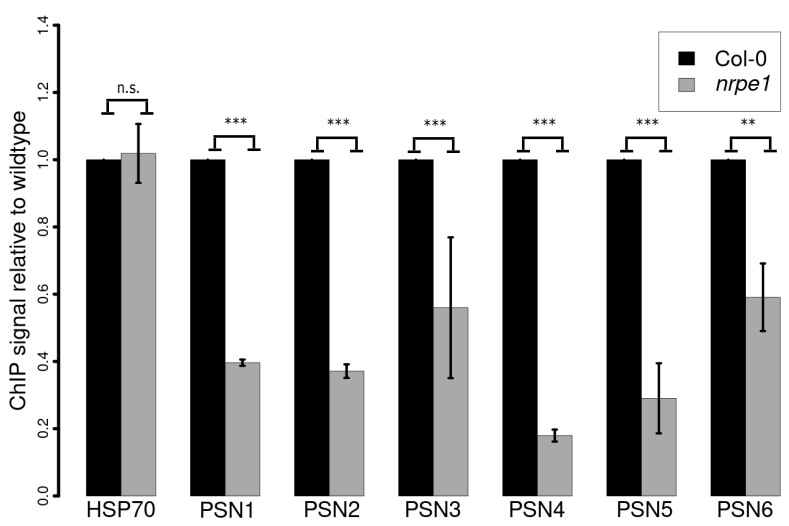
$B$ available under aCC-BY-NC-ND 4.0 International licensf.
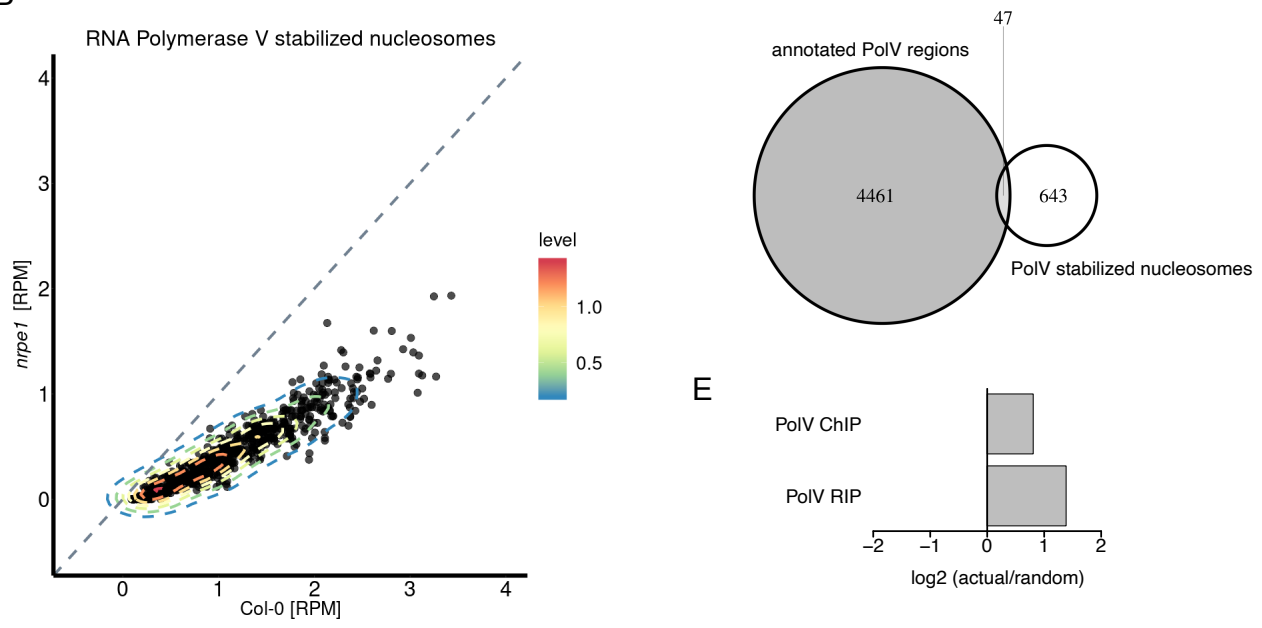

E

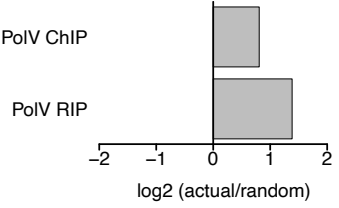

G

F

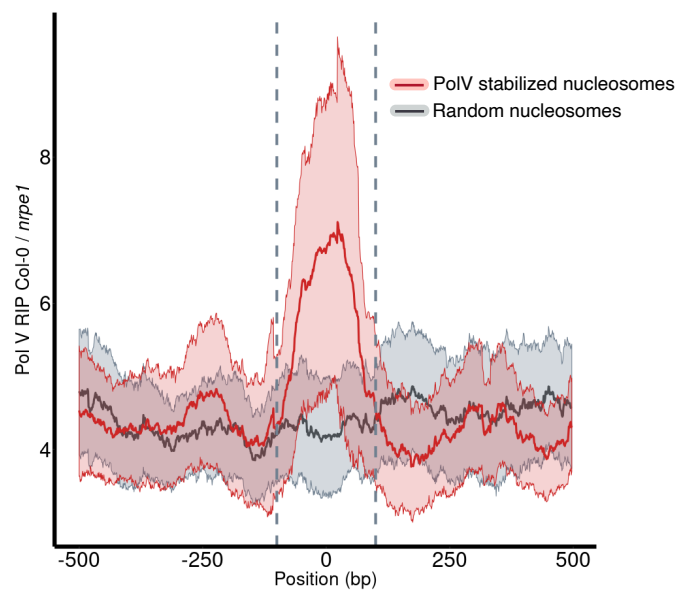

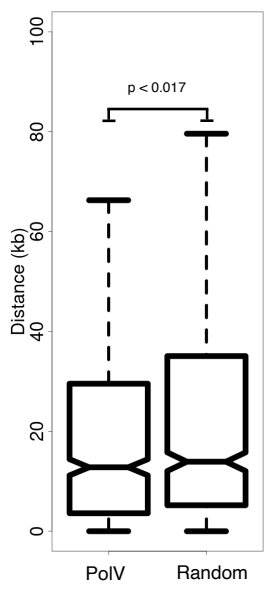


bioRxiv preprint dol: https://doi.org/10.1101/2020.10.29.359794; this version posted October 29, 2020. The copyright holder for this preprint

(which was not certified by peer review) is the author/funder, who has granted bioRxiv a license to display the preprint in perpetuity. It is made

Figure 2
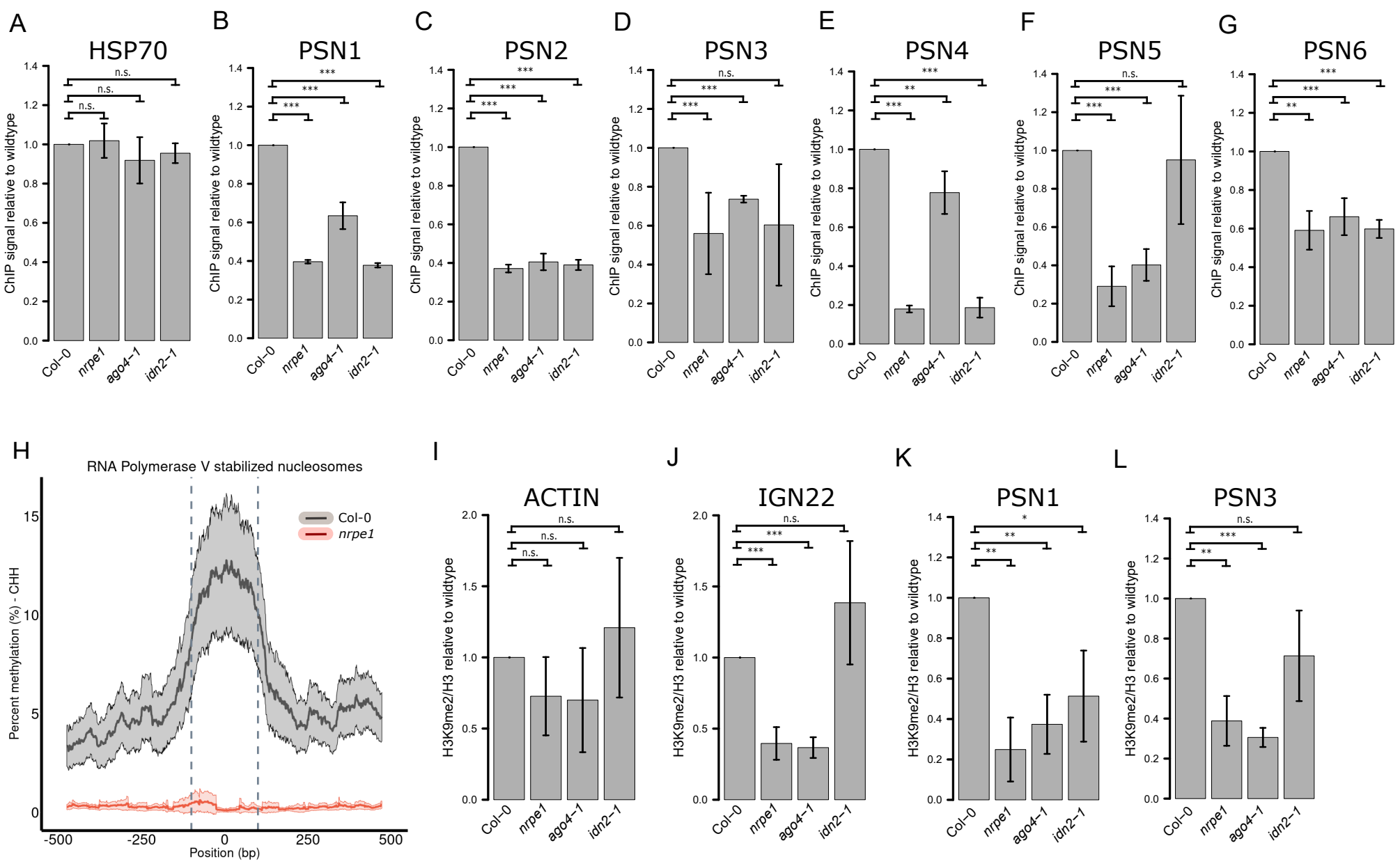
bioRxiv preprint doi: https://doi.org/10.1101/2020.10.29.359794: this version posted October 29,2020. The copyright holder for this preprint (which was not certified by peer review) is the author/funder, who has granted bioRxiv a license to display the preprint in perpetuity. It is made

Figure 3 available under aCC-BY-NC-ND 4.0 International license.

A

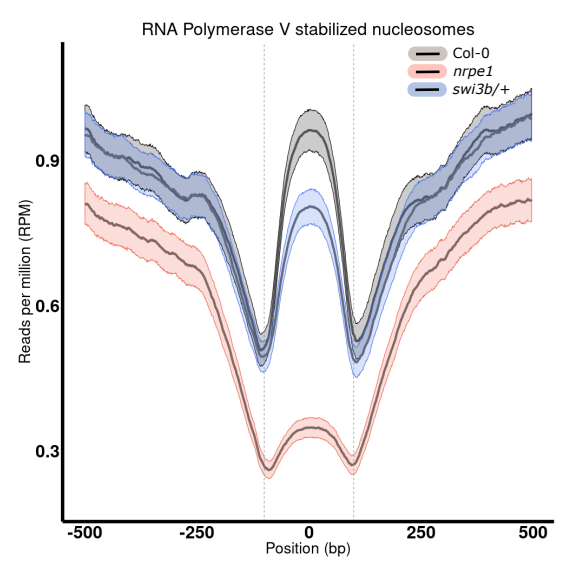

C

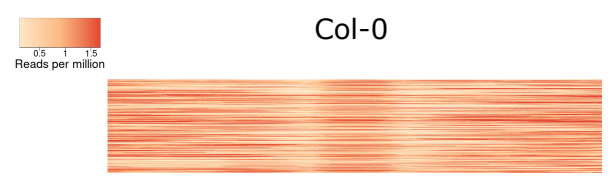

nrpe1

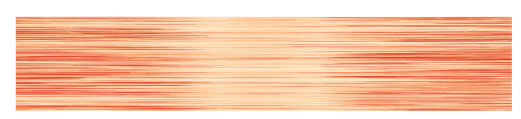

swi3b/+

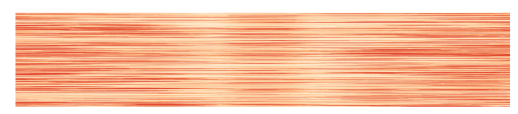

B

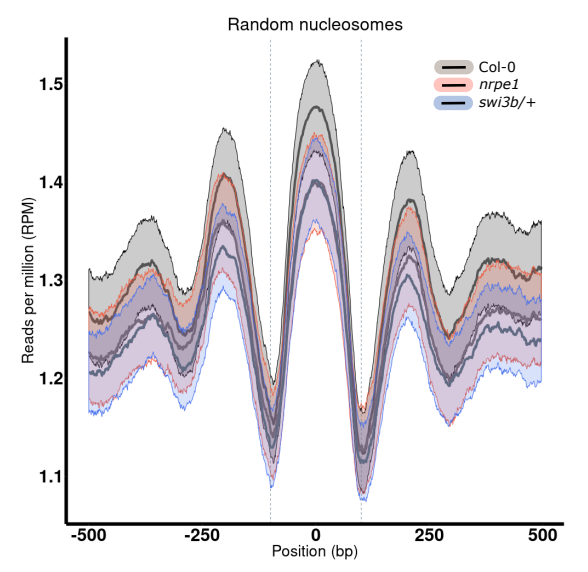

D

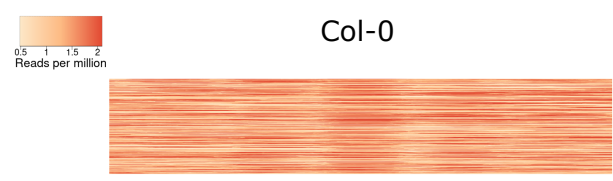

nrpe1

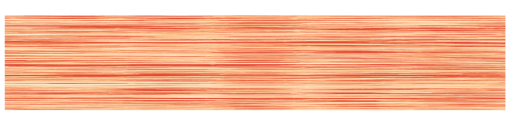

swi3b/+

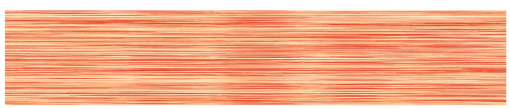


bioRxiv preprint doi: https://doi.org/10.1101/2020.10.29.359794; this version posted October 29, 2020. The copyright holder for this preprint (which was not certified by peer review) is the author/funder, who has granted bioRxiv a license to display the preprint in perpetuity. It is made available under aCC-BY-NC-ND 4.0 International license.

Figure 4

A

B

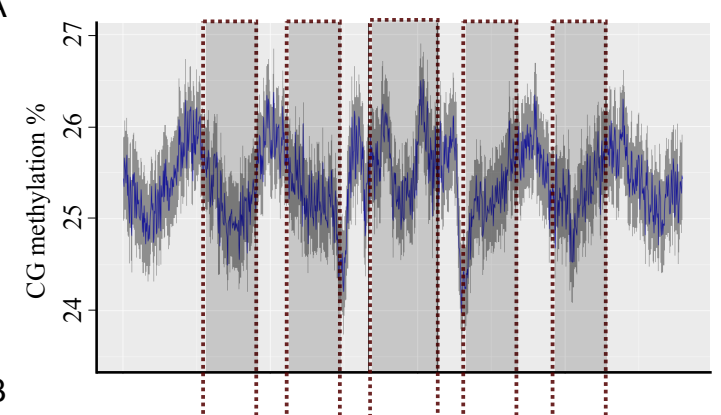

C
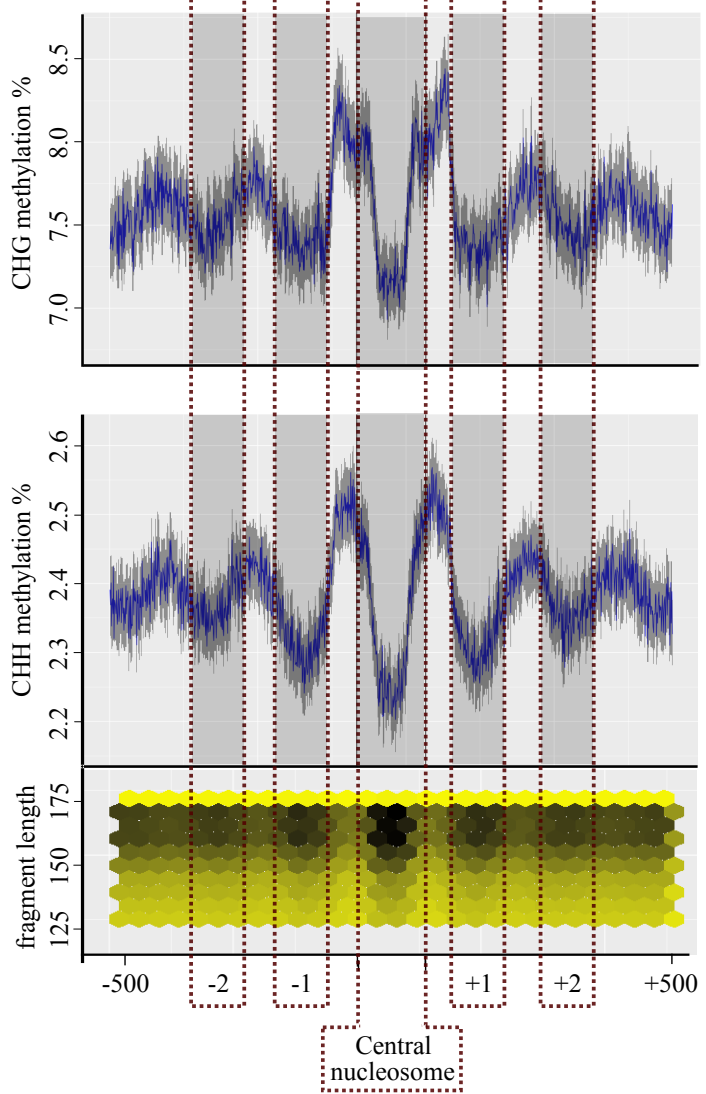

E

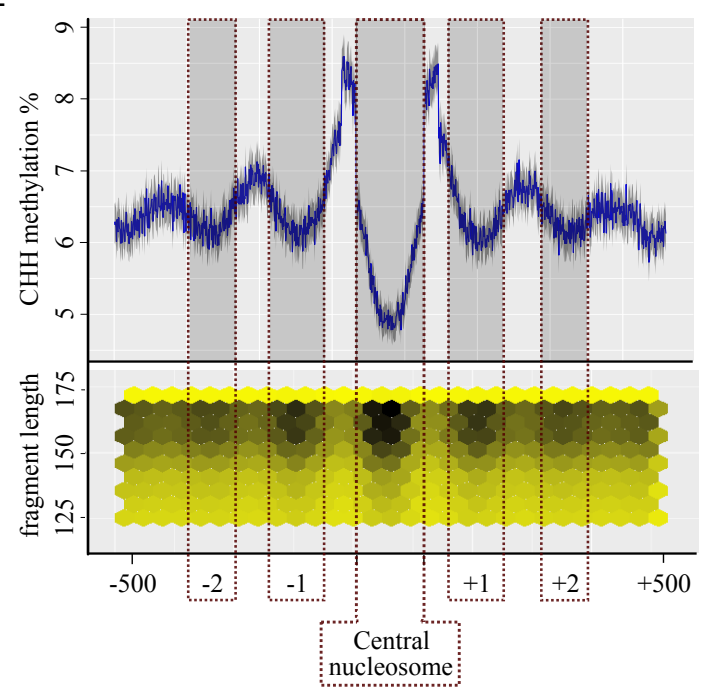

$\mathrm{F}$

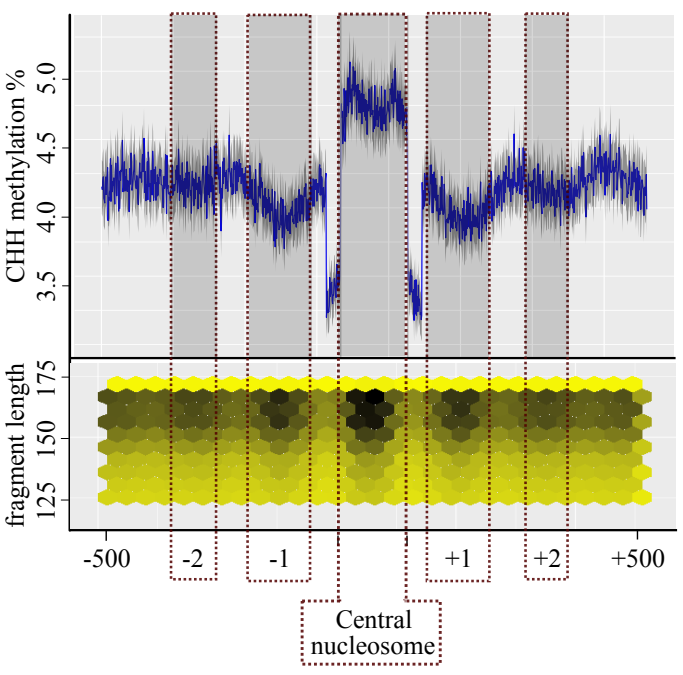


bioRxiv preprint doi: https://doi.org/10.1101/2020.10.29.359794; this version posted October 29, 2020. The copyright holder for this preprint (which was not certified by peer review) is the author/funder, who has granted bioRxiv a license to display the preprint in perpetuity. It is made Figure 5 available under aCC-BY-NC-ND 4.0 International license.

A

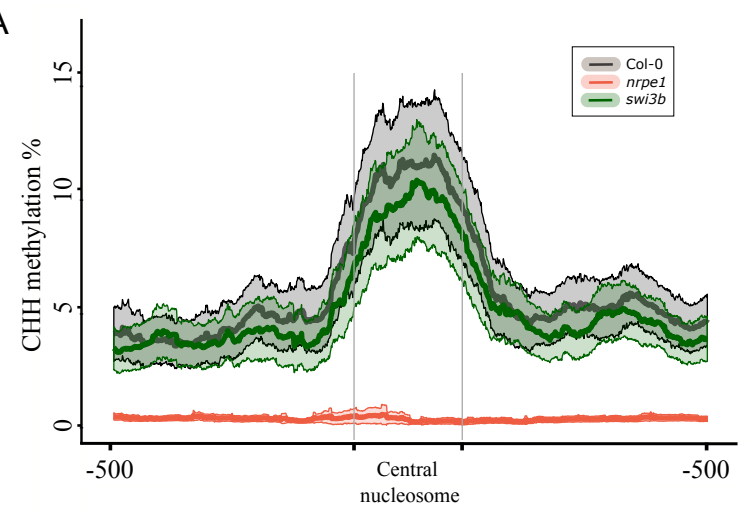

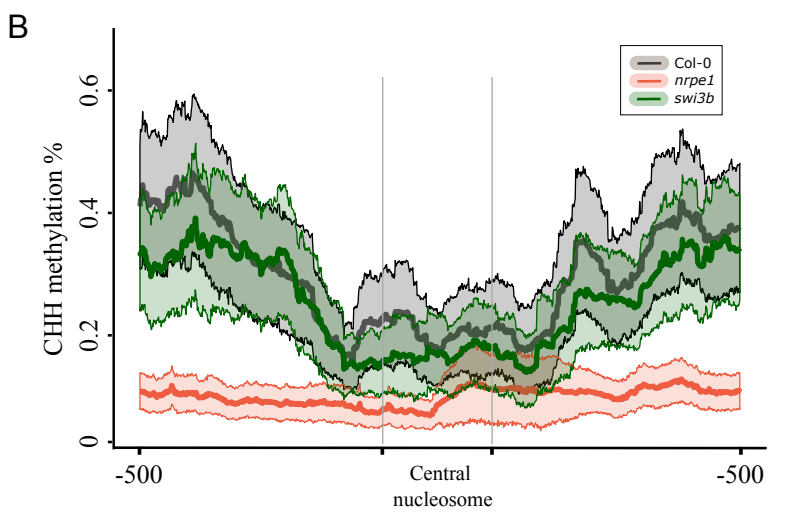


bioRxiv preprint doi: https://doi.org/10.1101/2020.10.29.359794: this version posted October 29, 2020. The copyright holder for this preprint (which was not certified by peer review) is the author/funder, who has granted bioRxiv a license to display the preprint in perpetuity. It is made Figure 6 available under aCC-BY-NC-ND 4.0 International license.

A

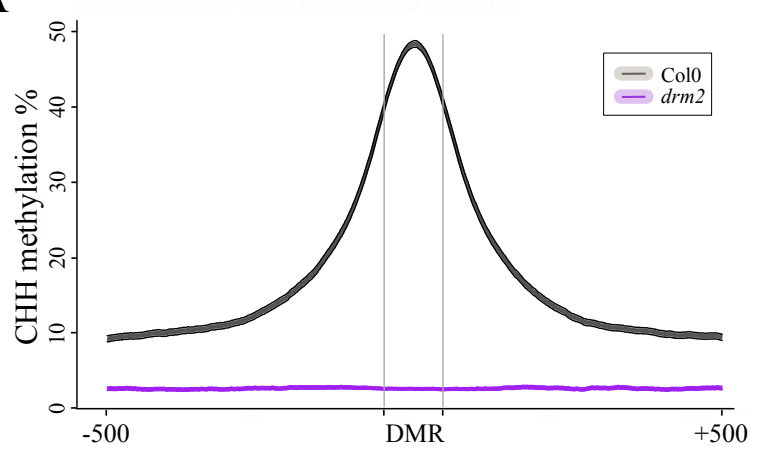

$\mathrm{C}$

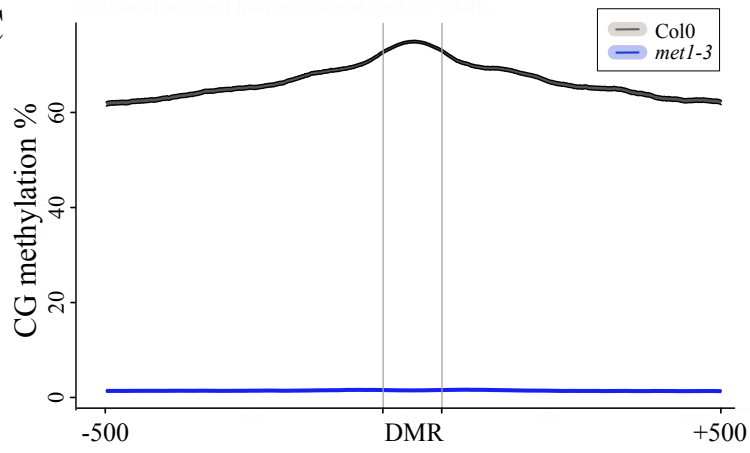

$\mathrm{E}$

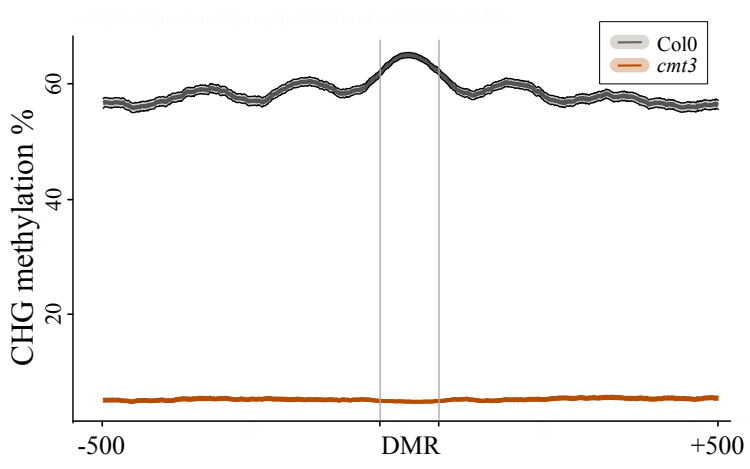

$\mathrm{B}$

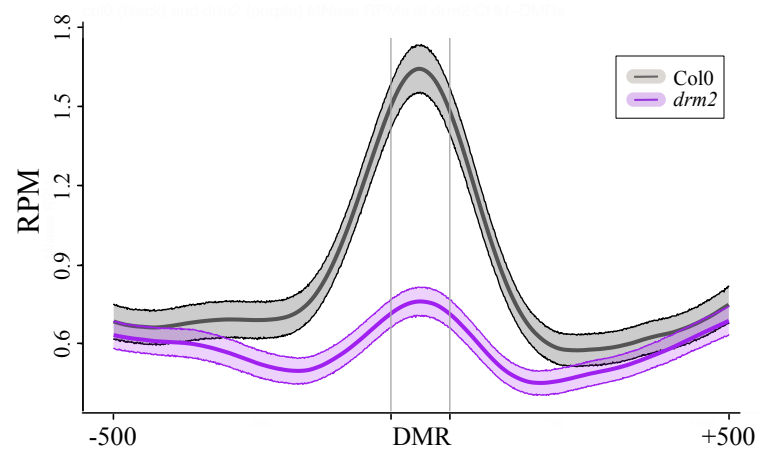

$\mathrm{D}$

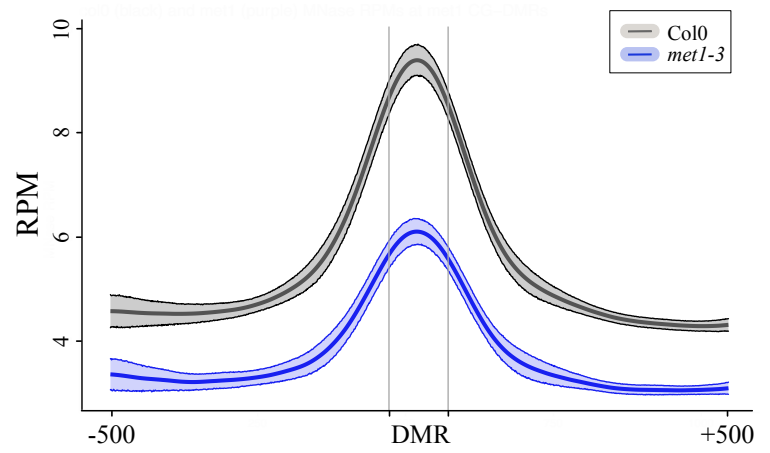

$\mathrm{F}$

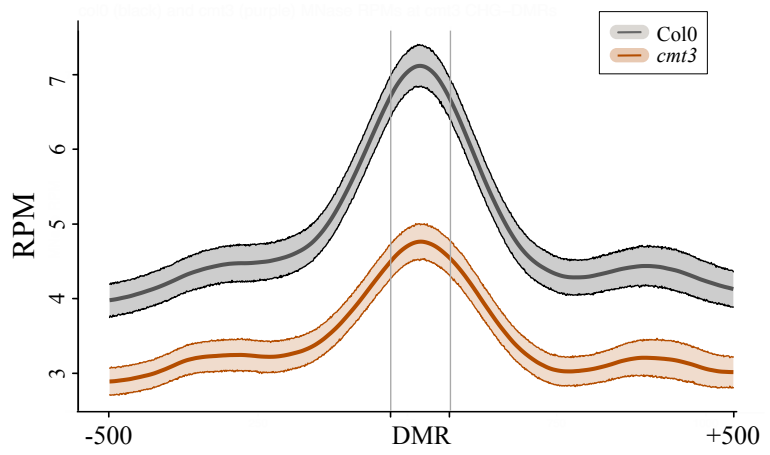


Table S1. Oligonucleotides used in this study, Related to the Experimental Procedures

\begin{tabular}{|c|c|c|c|}
\hline Locus & Name & Sequence (5'-3') & Application \\
\hline \multicolumn{4}{|c|}{ Nucleosome validation } \\
\hline \multirow[t]{2}{*}{ PSN1 } & MH487 & caggttgtgagttcgaatcgt & \multirow[t]{2}{*}{ ChIP-qPCR } \\
\hline & MH488 & catctccgttagccaccttt & \\
\hline \multirow[t]{2}{*}{ PSN2 } & MH489 & tgagattttaccgggtccac & \multirow[t]{2}{*}{ ChIP-qPCR } \\
\hline & MH490 & cccttatacgtaatttccatcaca & \\
\hline \multirow[t]{2}{*}{ PSN3 } & MH491 & ggagtgggatgtagactcgaa & \multirow[t]{2}{*}{ ChIP-qPCR } \\
\hline & MH492 & ctagtggtaccgcagggttt & \\
\hline \multirow{2}{*}{ PSN4 } & MH493 & cgatcggttcgatctcetta & \multirow{2}{*}{ ChIP-qPCR } \\
\hline & MH494 & taacggttcaacccgagaaa & \\
\hline \multirow[t]{2}{*}{ PSN5 } & MH495 & tctcccccacaatttctgtc & \multirow[t]{2}{*}{ ChIP-qPCR } \\
\hline & MH496 & aaatggacccctcattgtca & \\
\hline \multirow[t]{2}{*}{ PSN6 } & MH501 & acagatagcgctgtacagatttta & \multirow[t]{2}{*}{ ChIP-qPCR } \\
\hline & MH502 & tcatttgatatgcgttttgttt & \\
\hline \multirow[t]{2}{*}{ ACTIN2 } & Actin2-A118 & gagagattcagatgcccagaagtc & \multirow{2}{*}{$\begin{array}{l}\text { ChIP-qPCR } \\
\text { (Wierzbicki et al. 2008) }\end{array}$} \\
\hline & Actin2-A119 & tggattccagcagcttcca & \\
\hline \multirow[t]{2}{*}{ HSP70 } & A512 & ctcttcctcacacaatcataaaca & \multirow{2}{*}{$\begin{array}{l}\text { ChIP-qPCR } \\
\text { (Kumar \& Wigge } \\
\text { 2010) }\end{array}$} \\
\hline & A513 & cagaattgttcgccggaaag & \\
\hline
\end{tabular}

H3K9me2 validation

\begin{tabular}{llll}
\hline IGN22 & MH537 & cgggtccttggactcctgat & ChIP-qPCR \\
& MH538 & tcgtgaccggaataattaaatgg & (Rowley et al. 2011) \\
\hline \multirow{2}{*}{ ACTIN2 } & Actin2-A118 & gagagattcagatgcccagaagtc & $\begin{array}{l}\text { ChIP-qPCR } \\
\text { (Wierzbicki et al. 2008) }\end{array}$ \\
\cline { 2 - 4 } & Actin2-A119 & tggattccagcagcttcca & ChIP-qPCR \\
\hline PSN1 & MH487 & caggttgtgagttcgaatcgt & \\
\cline { 2 - 4 } & MH488 & catctccgttagccaccttt & ChIP-qPCR \\
\hline PSN3 & MH491 & ggagtgggatgtagactcgaa & \\
\cline { 2 - 4 } & MH492 & ctagtggtaccgcagggttt & \\
\hline
\end{tabular}


bioRxiv preprint doi: https://doi.org/10.1101/2020.10.29.359794; this version posted October 29, 2020. The copyright holder for this preprint (which was not certified by peer review) is the author/funder, who has granted bioRxiv a license to display the preprint in perpetuity. It is made Figure S1 available under aCC-BY-NC-ND 4.0 International license.

A

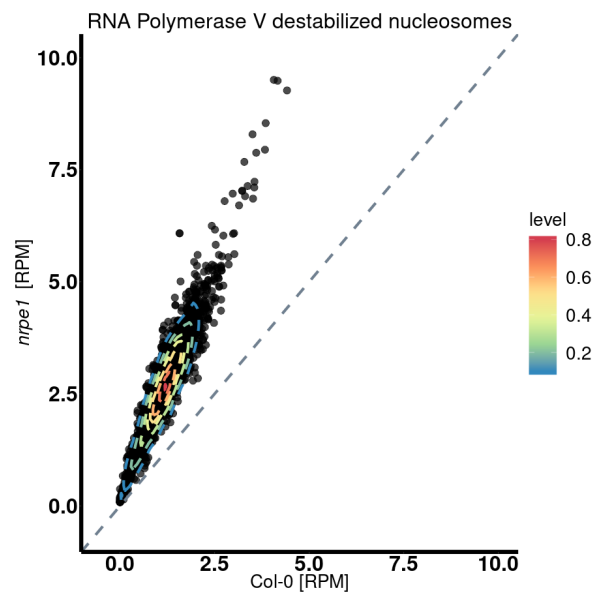

B

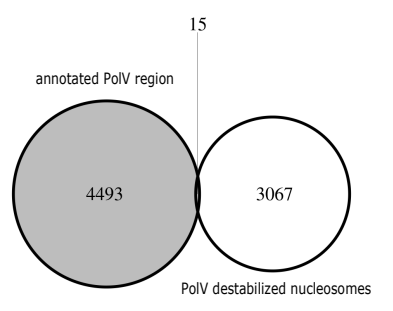

C

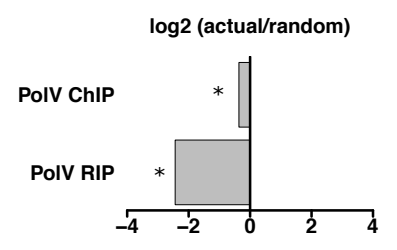

D

$\log 2$ (actual/random)

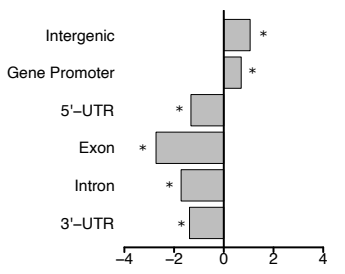

E

$\log 2$ (actual/random)

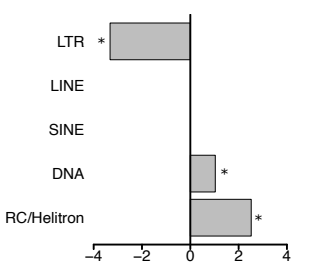


bioRxiv preprint doi: https://doi.org/10.1101/2020.10.29.359794; this version posted October 29, 2020. The copyright holder for this preprint (which was not certified by peer review) is the author/funder, who has granted bioRxiv a license to display the preprint in perpetuity. It is made

\section{Figure S2} available under aCC-BY-NC-ND 4.0 International license.

A

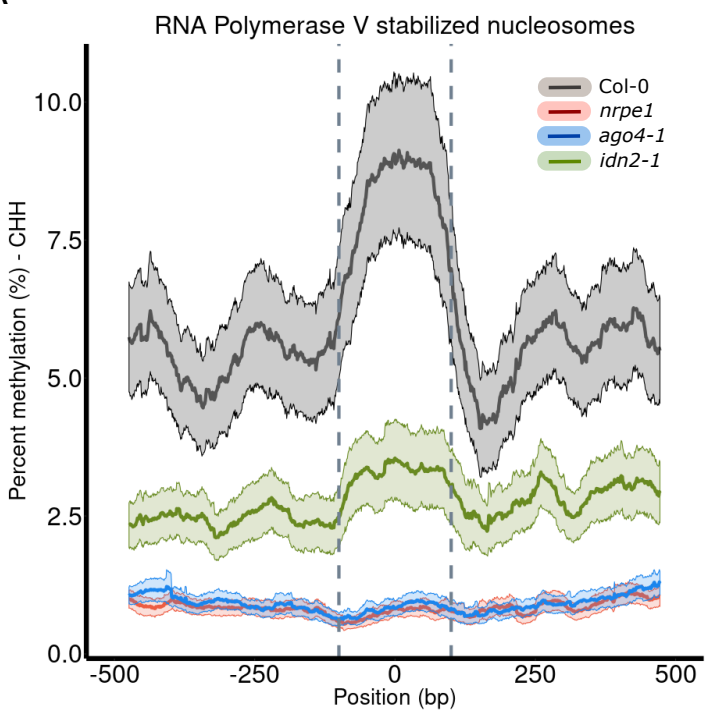


bioRxiv preprint doi: https://doi.org/10.1101/2020.10.29.359794; this version posted October 29, 2020. The copyright holder for this preprint (which was not certified by peer review) is the author/funder, who has granted bioRxiv a license to display the preprint in perpetuity. It is made available under aCC-BY-NC-ND 4.0 International license.

Figure S3

A

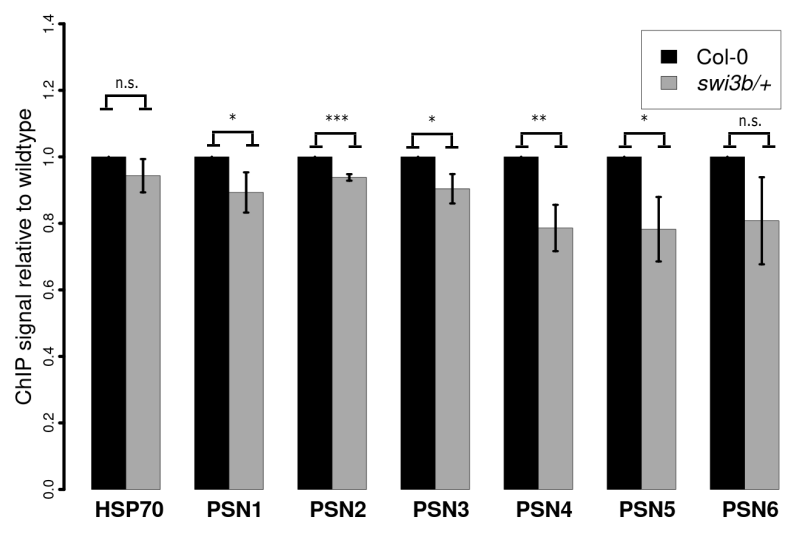


bioRxiv preprint doi: https://doi.org/10.1101/2020.10.29.359794; this version posted October 29, 2020. The copyright holder for this preprint (which was not certified by peer review) is the author/funder, who has granted bioRxiv a license to display the preprint in perpetuity. It is made available under aCC-BY-NC-ND 4.0 International license.

Figure S4

A

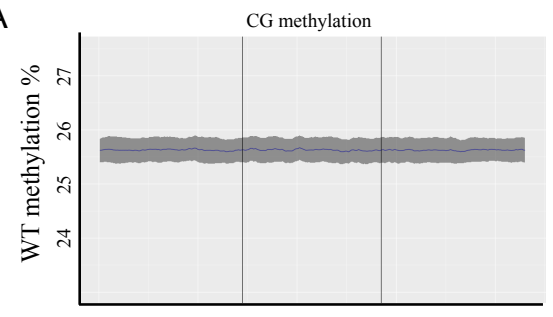

B

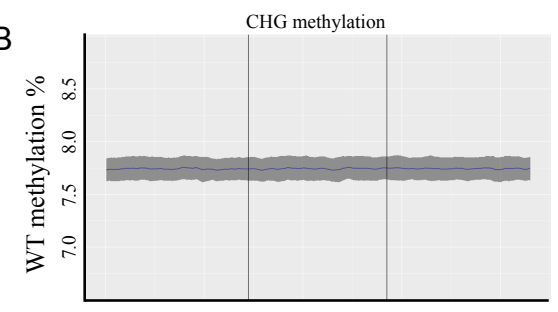

$\mathrm{C}$

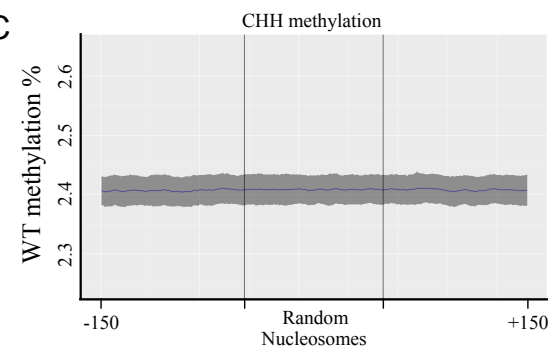

D
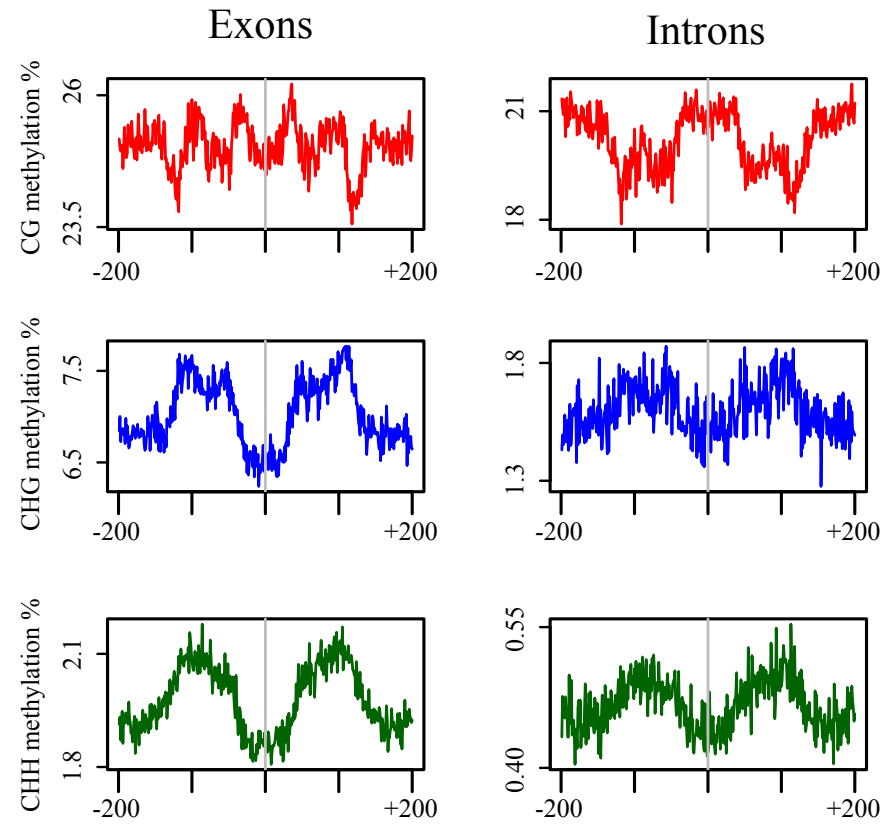

$\mathrm{E}$

Gene Bodies
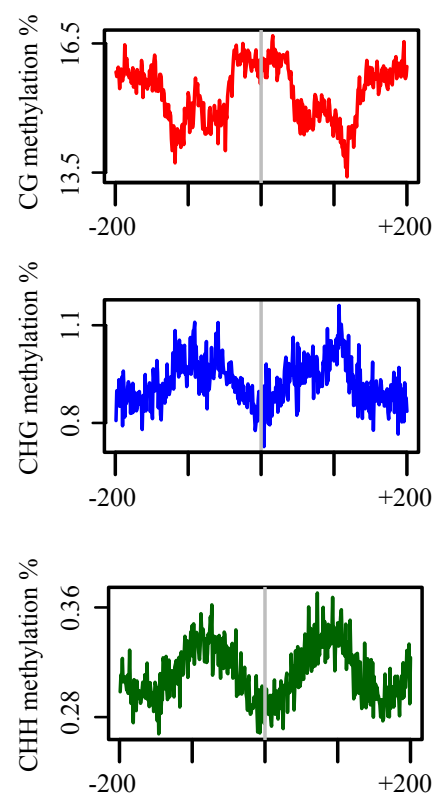

TSS
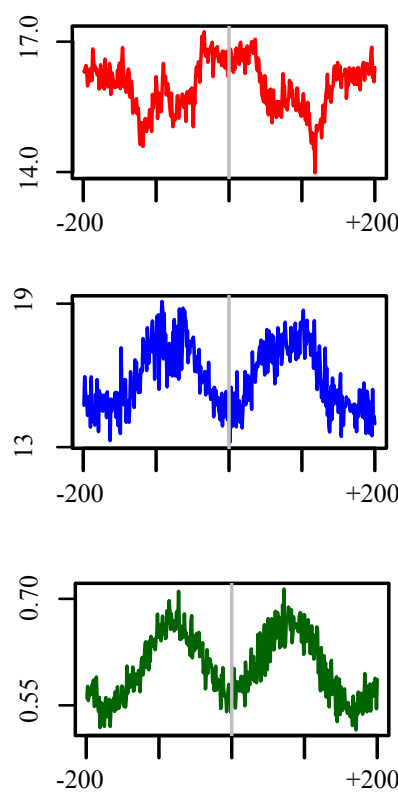

Intergenic
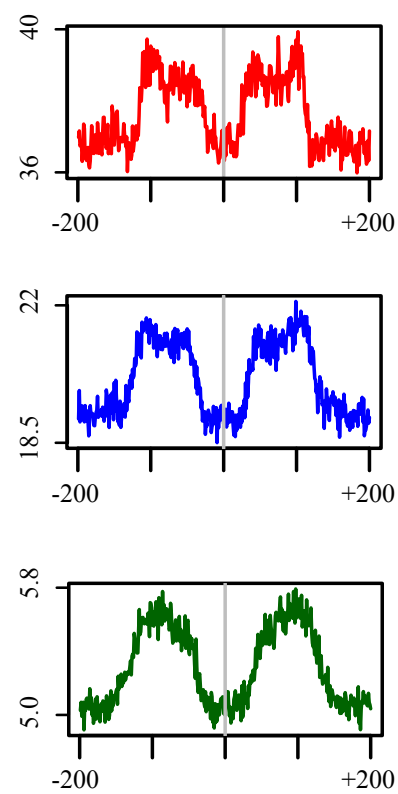

Transposons
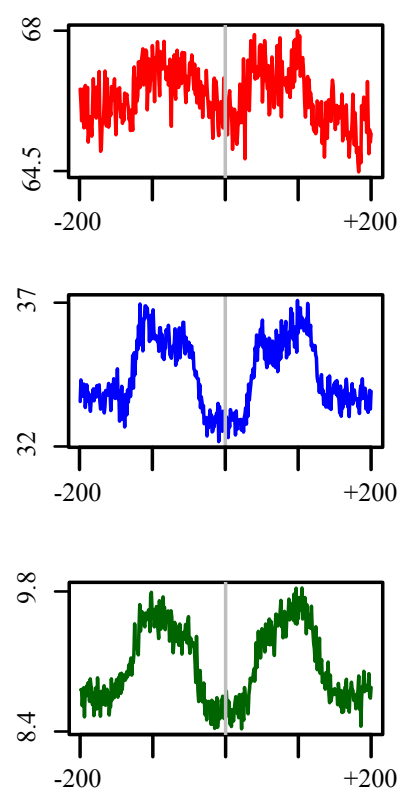
bioRxiv preprint doi: https://doi.org/10.1101/2020.10.29.359794; this version posted October 29, 2020. The copyright holder for this preprint (which was not certified by peer review) is the author/funder, who has granted bioRxiv a license to display the preprint in perpetuity. It is made available under aCC-BY-NC-ND 4.0 International license.

Figure S5

A

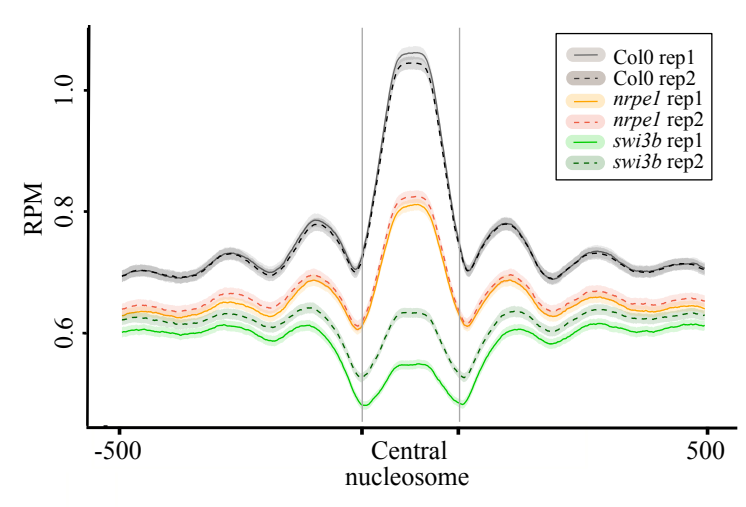

C
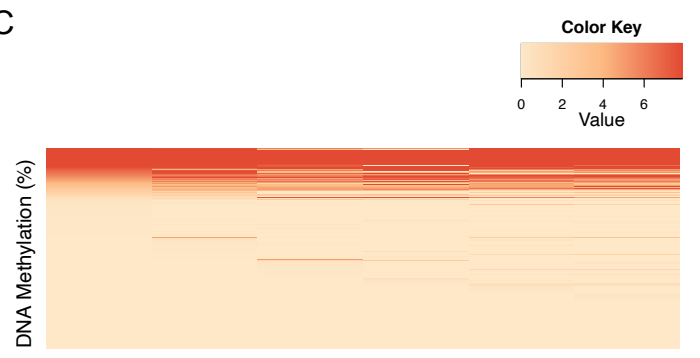

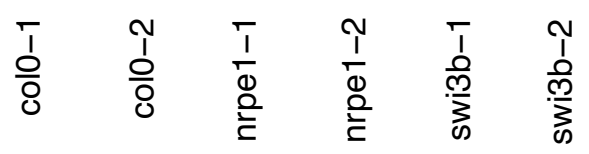

B

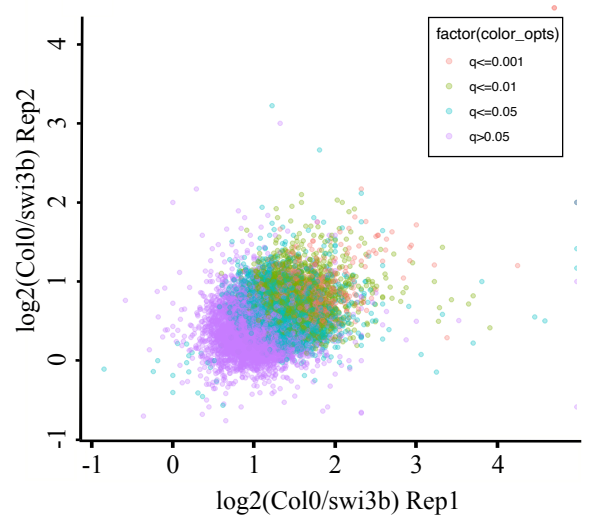


bioRxiv preprint doi: https://doi.org/10.1101/2020.10.29.359794; this version posted October 29,2020. The copyright holder for this preprint (which was not certified by peer review) is the author/funder, who has granted bioRxiv a license to display the preprint in perpetuity. It is made Figure S6 available under aCC-BY-NC-ND 4.0 International license.

A

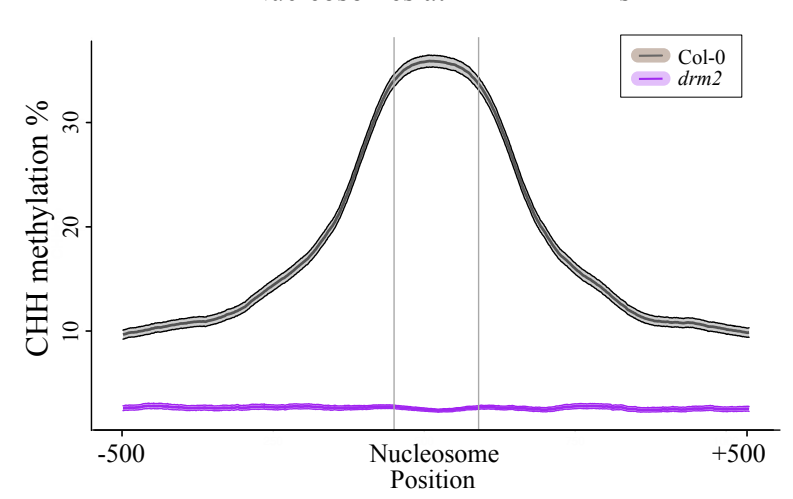

$\mathrm{B}$

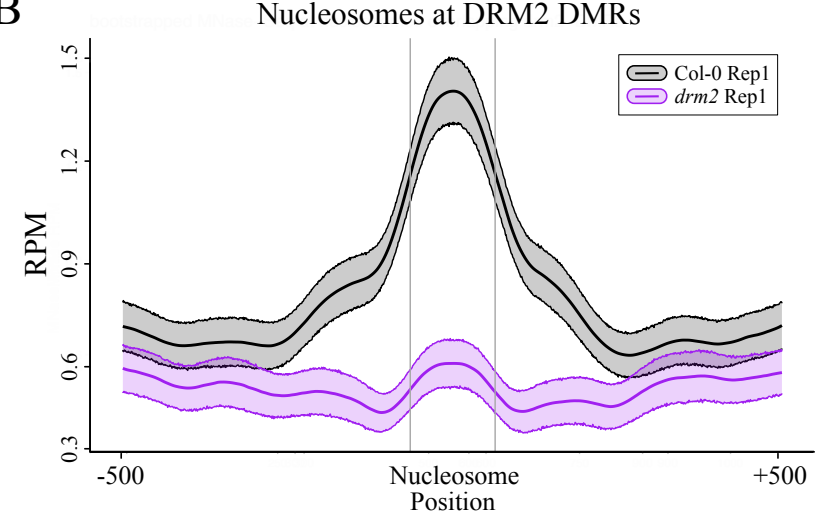

$\mathrm{C}$

Pol V Stabilized nucleosomes

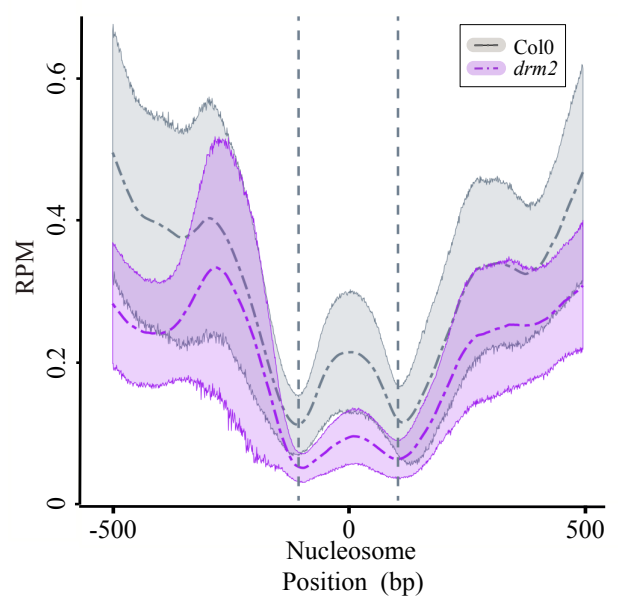

